\title{
Developmental RacGAP $\alpha 2$-Chimaerin Signaling Is a Determinant of the Morphological Features of Dendritic Spines in Adulthood
}

\author{
Ryohei Iwata, ${ }^{1,2}$ Hiroshi Matsukawa, ${ }^{3}$ Kosuke Yasuda, ${ }^{3}$ Hidenobu Mizuno, ${ }^{1,2}$ Shigeyoshi Itohara, ${ }^{3}$ and Takuji Iwasato ${ }^{1,2}$ \\ ${ }^{1}$ Division of Neurogenetics, National Institute of Genetics, Mishima, Shizuoka 411-8540, Japan, ${ }^{2}$ Department of Genetics, Sokendai, Mishima, Shizuoka \\ 411-8540, Japan, and 3 ${ }^{3}$ aboratory for Behavioral Genetics, Riken Brain Science Institute, Wako, Saitama 351-0198, Japan
}

Morphological characteristics of dendritic spines form the basis of cognitive ability. However, molecular mechanisms involved in finetuning of spine morphology during development are not fully understood. Moreover, it is unclear whether, and to what extent, these developmental mechanisms determine the normal adult spine morphological features. Here, we provide evidence that $\alpha 2$-isoform of Rac-specific GTPase-activating protein $\alpha$-chimaerin ( $\alpha 2$-chimaerin) is involved in spine morphological refinement during late postnatal period, and furthermore show that this developmental $\alpha 2$-chimaerin function affects adult spine morphologies. We used a series of mice with global and conditional knock-out of $\alpha$-chimaerin isoforms ( $\alpha 1$-chimaerin and $\alpha 2$-chimaerin). $\alpha 2$-Chimaerin disruption, but not $\alpha 1$-chimaerin disruption, in the mouse results in an increased size (and density) of spines in the hippocampus. In contrast, overexpression of $\alpha 2$-chimaerin in developing hippocampal neurons induces a decrease of spine size. Disruption of $\alpha 2$-chimaerin suppressed EphA-mediated spine morphogenesis in cultured developing hippocampal neurons. $\alpha 2$-Chimaerin disruption that begins during the juvenile stage results in an increased size of spines in the hippocampus. Meanwhile, spine morphologies are unaltered when $\alpha 2$ chimaerin is deleted only in adulthood. Consistent with these spine morphological results, disruption of $\alpha 2$-chimaerin beginning in the juvenile stage led to an increase in contextual fear learning in adulthood; whereas contextual learning was recently shown to be unaffected when $\alpha 2$-chimaerin was deleted only in adulthood. Together, these results suggest that $\alpha 2$-chimaerin signaling in developmental stages contributes to determination of the morphological features of adult spines and establishment of normal cognitive ability.

Key words: cognitive development; conditional knock-out mouse; hippocampus; mouse genetics

Significance Statement

Recent studies of neurodevelopmental disorders in humans and their animal models have led to an attractive hypothesis that spine morphogenesis during development forms the basis of adult cognition. In particular, the roles of Rac and its regulators, such as Rac-specific GTPase-activating proteins (RacGAPs) and Rac guanine nucleotide exchange factors, are a topic of focus in spine morphogenesis and cognitive ability. Using a series of mice with global and conditional knock-out (KO) of RacGAP $\alpha$-chimaerin isoforms ( $\alpha 1$-chimaerin and $\alpha 2$-chimaerin), we provide compelling evidence demonstrating that $\alpha 2$-chimaerin is involved in spine morphological refinement during late postnatal development and that this developmental $\alpha 2$-chimaerin function affects adult spine morphologies. Furthermore, our results clearly showed that $\alpha 2$-chimaerin signaling during late postnatal development contributes to normal cognitive ability in adult mice.

\section{Introduction}

In the mammalian brain, most excitatory synapses are formed on small protrusions of the dendritic membrane known as spines

Received Feb. 1, 2015; revised Aug. 6, 2015; accepted Sept. 2, 2015.

Author contributions: R.I., S.I., and T.I. designed research; R.I., H. Matsukawa, and K.Y. performed research; H. Mizuno contributed unpublished reagents/analytic tools; R.I. and T.I. analyzed data; R.I., S.I., and T.I. wrote the paper.

This work was supported by the Japanese Society for the Promotion of Science (JSPS) Science Research Funds [Kagaku Kenkyu Hi (Kakenhi)] 11J03717 (to R.I.); the First program (Funding Program for World-Leading Innovative R\&D on Science and Technology) and National Institute of Genetics Collaborative Research (to S.I.); and JSPS Kakenhi
(Nimchinsky et al., 2002). Morphological features of dendritic spines, such as size and density, are fundamental to synaptic function (Kasai et al., 2010). The size of the spine correlates with the area of postsynaptic density and strength of the synapse, and the 
density of the spine indicates the number of excitatory synaptic inputs received by that dendrite. Accumulating evidence suggests that the morphological features of spines contribute to cognitive ability. For example, animals housed in enriched environments exhibit increased spine density and higher cognitive abilities (Rampon et al., 2000; van Praag et al., 2000), whereas human patients with schizophrenia and animal models of this disease exhibit decreased spine size and density and lower cognitive abilities (Glantz and Lewis, 2000; Penzes et al., 2011).

Spine morphogenesis occurs extensively during the late postnatal period (Yuste and Bonhoeffer, 2004; Penzes et al., 2011). In the mature brain, spines still change their size and density from the "baseline morphological features of spines" in response to a variety of stimuli (Bourne and Harris, 2008), and this spine remodeling in adulthood is considered to be the morphological basis of neural circuit remodeling underlying brain function, including learning and memory. The morphology of dendritic spines primarily relies on actin cytoskeleton remodeling by the Rho-family of small GTPases, such as RhoA, Rac, and Cdc42 (Ethell and Pasquale, 2005). Accumulating evidence suggests that Rac and its regulators [e.g., Rac guanine nucleotide exchange factors (RacGEFs) and Rac-specific GTPase-activating proteins (RacGAPs)] are important determinants of spine morphology (Ma et al., 2008; Nakazawa et al., 2008; Zhang and Macara, 2008; Cahill et al., 2009; Oh et al., 2010; Carlson et al., 2011; Charrier et al., 2012; Cheadle and Biederer, 2012; Ramakers et al., 2012; Raynaud et al., 2014). However, because most previous studies relied on data from in vitro experiments and/or phenotypes of global $\mathrm{KO}$ mice, the significance of developmental Rac signaling for adult spine morphological features is not well understood.

$\alpha$-Chimaerin ( $\alpha$-chimerin) is a RacGAP that negatively regulates Rac activity (Hall et al., 1990). $\alpha$-Chimaerin has two splicing isoforms, $\alpha 1$-chimaerin and $\alpha 2$-chimaerin, which are transcribed from distinct promoters (Hall et al., 1993; Dong et al., 1995). $\alpha 1$-Chimaerin is dominantly expressed in adulthood, whereas $\alpha 2$-chimaerin is preferentially expressed during development (Lim et al., 1992; Hall et al., 2001). $\alpha 2$-Chimaerin regulates midline axon guidance of the corticospinal tract and the spinal central pattern generator, and a loss of function of this protein leads to hopping gaits in mice, as reported previously by us and in other studies (Beg et al., 2007; Iwasato et al., 2007; Wegmeyer et al., 2007). These reports suggest important roles for $\alpha 2$-chimaerin in axon guidance during development. In contrast, although $\alpha 2$-chimaerin is enriched not only in axonal growth cones but also in dendritic spines (Iwasato et al., 2007; Shi et al., 2007), the involvement of $\alpha 2$-chimaerin in spine morphogenesis has never been reported to the best of our knowledge.

In this study, by using a series of mice with global and conditional $\mathrm{KO}$ of $\alpha$-chimaerin isoforms ( $\alpha 1$-chimaerin and $\alpha 2$ chimaerin), we provide the first evidence that $\alpha 2$-chimaerin has an important role in dendritic spine morphogenesis during development. Furthermore, and more importantly, we here show that $\alpha 2$-chimaerin signaling during late postnatal development contributes to the determination of the basal morphological features of adult hippocampal spines and to the establishment of normal cognitive ability in adulthood.

The authors declare no competing financial interests.

Correspondence should be addressed to either Takuji Iwasato or Ryohei Iwata, Division of Neurogenetics, National Institute of Genetics (NIG), 1111 Yata, Mishima, Shizuoka 411-8540, Japan. E-mail: tiwasato@nig.ac.jp or riwata@nig.ac.jp.

DOI:10.1523/JNEUROSCI.0419-15.2015

Copyright $\odot 2015$ the authors $\quad 0270-6474 / 15 / 3513729-17 \$ 15.00 / 0$
Table 1. Primer information

\begin{tabular}{|c|c|}
\hline Sequence & Purpose \\
\hline GGAGTTCCAGCTCCATTGTG & Genotyping for $\alpha$ ChnKO mice \\
\hline CAAGGAAAGCCCTCCAGATG & Genotyping for $\alpha$ ChnKO mice \\
\hline GTACACTAGGATCTCAGCTC & Genotyping for $\alpha 1$-floxed mice \\
\hline AGCTTGGGTAGTAACAAGAC & Genotyping for $\alpha 1$-floxed mice \\
\hline ATGCAGTAGCACACTTCAGC & Genotyping for $\alpha 2 \mathrm{~K} 0$ and $\alpha 2$-floxed mice \\
\hline AGTGCTGGCCTTTAAGTATG & Genotyping for $\alpha 2 \mathrm{~K} 0$ mice \\
\hline AACTATCACACTGTTATGAG & Genotyping for $\alpha 2$-floxed mice \\
\hline ACCTGATGGACATGTTCAGGGATCG & Genotyping Emx1Cre Kl- $\Delta$ Neo mice \\
\hline TCCGGTTATTCAACTTGCACCATGC & Genotyping Emx1Cre Kl- $\Delta$ Neo mice \\
\hline GTCGACATGGTGAGCAAGGGCGAGGA & Construction of pK173 \\
\hline GAATTCCTACACCTTCCTCTTCTTCTTGG & Construction of pK173 \\
\hline $\begin{array}{l}\text { AGCTGAATTCGCCACCATGAGCGAGCTG } \\
\text { ATCAAGGAG }\end{array}$ & Construction of pK165 \\
\hline $\begin{array}{l}\text { AGCTGGATCCTCATCTGTGCCCCAGTTTGC } \\
\text { TAGG }\end{array}$ & Construction of pK165 \\
\hline AGTCGACGTCCACCATGGTGCCCAAGA & Construction of pK166 \\
\hline TGGATCCGTCCCCATCCTCGAGCAG & Construction of pK166 \\
\hline $\begin{array}{l}\text { AGGATCCGGAAGCGGAGCTACTAACTTCAGCCTGCT } \\
\text { GAAGCAGGCTGGAGACGTGGAGGAGAACCCT } \\
\text { GGACCTATGAGCGAGCTGATCA }\end{array}$ & Construction of pK166 \\
\hline AGAATTCTCATCTGTGCCCCAGTTTGC & Construction of pK166 \\
\hline GACTCTACGGAGTGTCAGGATTTAGTG & Construction of pK193, pK197, and pK195 \\
\hline GACACTCCGTAGAGTCCTTCAGAATT & Construction of pK193, pK197, and pK195 \\
\hline GAGTTTCCCCACACTGAGTG & Titration of AAV \\
\hline GAGGCTTGAGAATGAACCAAGA & Titration of AAV \\
\hline
\end{tabular}

\section{Materials and Methods}

\section{Mouse lines and genotyping}

$\alpha \mathrm{ChnKO}, \alpha 2 \mathrm{KO}, \alpha 2$-floxed, $\alpha 1$-floxed, and Emx1Cre KI- $\Delta$ Neo mice were previously reported (Iwata et al., 2014). PCR primer pairs for genotyping are as follows: $5^{\prime}$-GGAGTTCCAGCTCCATTGTG-3'/5'CAAGGAAAGCCCTCCAGATG-3' (137 bp and no bands for WT and $\alpha$ ChnKO alleles, respectively); $5^{\prime}$-GTACACTAGGATCTCAGCTC-3'। 5'-AGCTTGGGTAGTAACAAGAC-3' (471 and 583 bp bands for WT and $\alpha 1$-floxed alleles, respectively); 5'-ATGCAGTAGCACACTTCA GC-3'/5'-AGTGCTGGCCTTTAAGTATG-3' (421 bp and $1.6 \mathrm{~kb}$ bands for $\alpha 2 \mathrm{KO}$ and WT alleles, respectively); $5^{\prime}$-ATGCAGTAGCACACTT CAGC-3'/5'-AACTATCACACTGTTATGAG-3' (328 and 408 bp bands for WT and $\alpha 2$-floxed alleles, respectively); $5^{\prime}$-ACCTGATGGACATGT TCAGGGATCG-3' ${ }^{\prime} 5^{\prime}$-TCCGGTTATTCAACTTGCACCATGC-3' ${ }^{\prime}$ (108 bp band for EmxlCre $\mathrm{KI}-\Delta \mathrm{Neo}$ ). The primers are listed in Table 1.

Quantitative analyses in Figures 1, 2, 3D, 4-6, and 8 were conducted under strict genotype-blind conditions, and the genotypes of mice were disclosed to the experimenter only after all experiments and analyses were completed.

\section{DNA constructs}

pAAV-EF1 $\alpha$-GFPCre-WPRE-pA (pAAV-GFPCre). The GFPCre sequence was amplified from the AAV-GFPCre (Addgene, 49056) using the following primers: 5 '-GTCGACATGGTGAGCAAGGGCGAGGA3'/5'-GAATTCCTACACCTTCCTCTTCTTCTTGG-3'. The pAAVGFPCre ( $\mathrm{pK} 173$ ) was generated by ligation of GFPCre into the SalI/ EcoRI sites of the pAAV-EF1 $\alpha$-DIO EYFP vector (Addgene, 27056).

$p A A V-E F 1 \alpha-R F P-W P R E-p A$ ( $p A A V-R F P)$. The RFP sequence was amplified from TurboRFP (Evrogen) using the following primer pair: 5'-AGCTGAATTCGCCACCATGAGCGAGCTGATCAAGGAG-3'/5' AGCTGGATCCTCATCTGTGCCCCAGTTTGCTAGG-3'. The pAAVRFP (pK165) was generated by ligation of RFP into the blunted Bam $\mathrm{HI} / \mathrm{EcoRV}$ site of the pAAV-EF1 $\alpha$-DIO EGFP-WPRE-pA (Addgene, 37084).

pAAV-EF1 $\alpha-C r e-P 2 A-R F P-W P R E-p A(p A A V-C r e-R F P)$. The Cre sequence was amplified from pBlue.iCre (Shimshek et al., 2002) using the following primer pair: 5'-AGTCGACGTCCACCATGGTGCCCAAGA3'/5'-TGGATCCGTCCCCATCCTCGAGCAG-3'. The P2A-RFP sequence was amplified from TurboRFP (Evrogen) using the following 
A

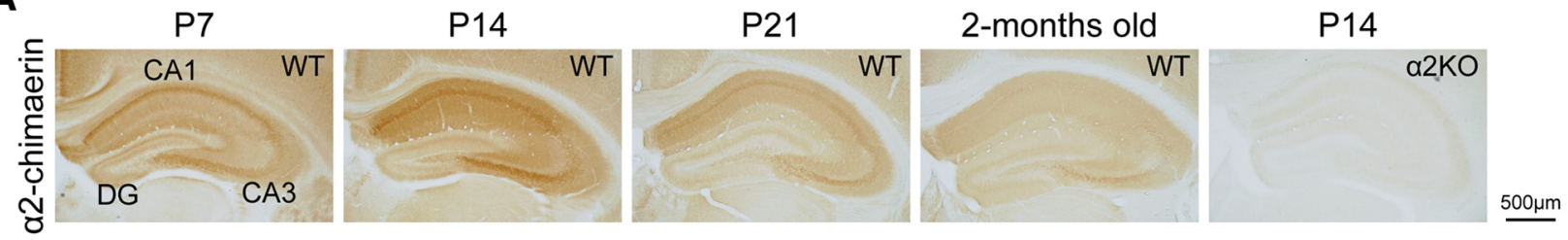

B
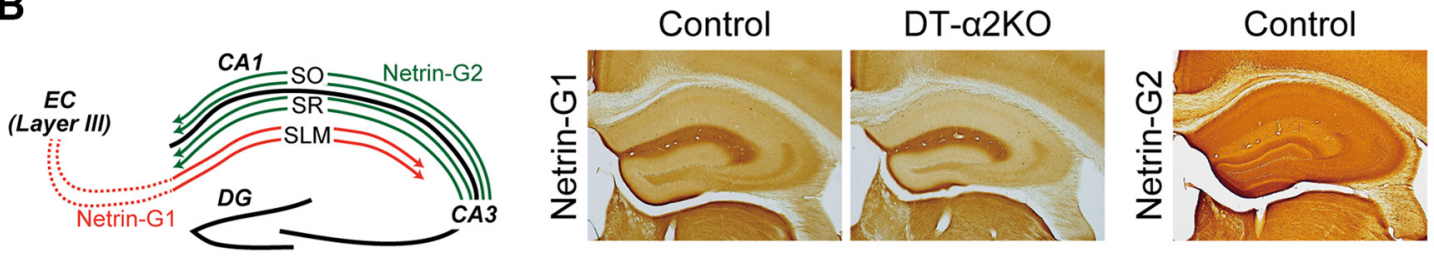

DT- $\alpha 2 \mathrm{KO}$

C
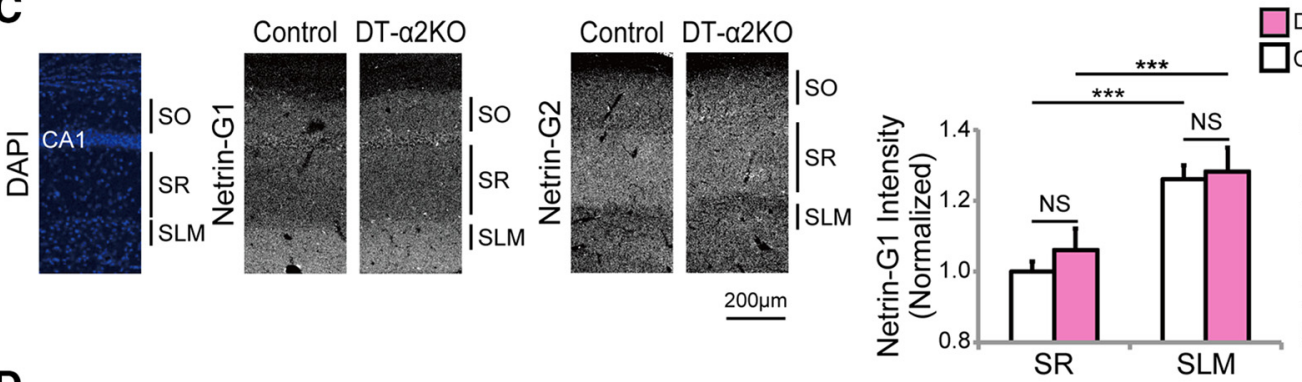

$\square \mathrm{DT}-\alpha 2 \mathrm{KO}(\mathrm{n}=6)$

D

Control
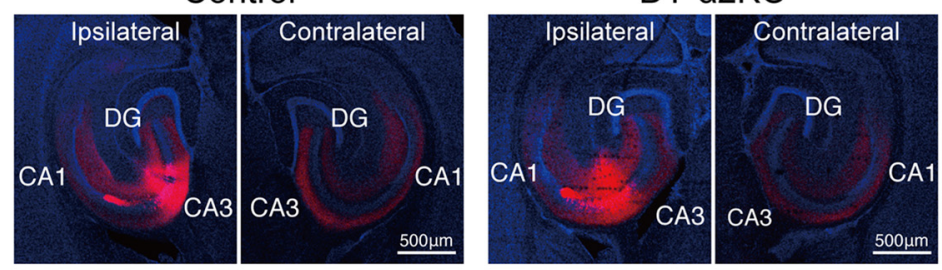

E

Control
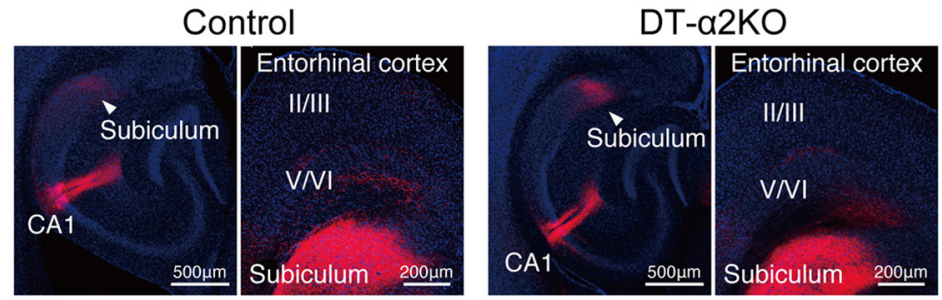

F
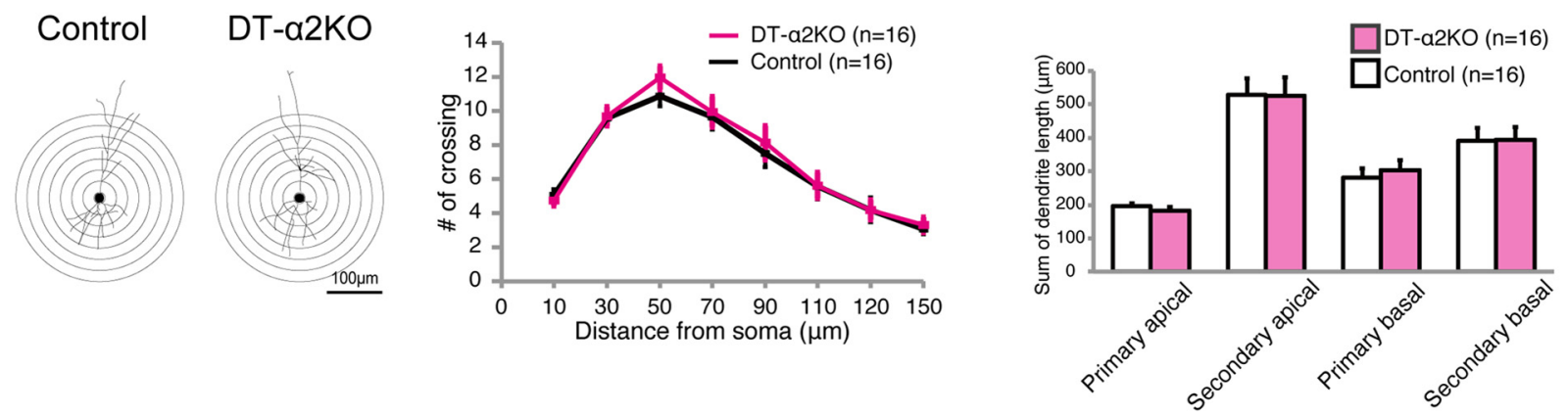

Figure 1. Axonal projections and dendritic morphologies in the hippocampus of DT- $\alpha 2 \mathrm{KO}$ mice. $\boldsymbol{A}$, Immunohistochemical analyses using anti- $\alpha 2$-chimaerin antibody revealed that expression levels of $\alpha 2$-chimaerin in the hippocampus were highest at $\sim$ P14 and decreased toward adulthood ( 2 months old). DG, Dentate gyrus. $\boldsymbol{B}$, Immunostaining patterns of netrin-G1 and netrin-G2 were similar between control and DT- $\alpha 2$ KO mice in adulthood. Netrin-G1 and netrin-G2 are pathway-specific axonal markers (Nishimura-Akiyoshi et al., 2007). For example, axons of entorhinal cortex (EC) layer III neurons that terminate on the stratum lacunosum-moleculare (SLM) of the hippocampus CA1 express netrin-G1, whereas the axons of CA3 neurons that terminate on the stratum radiatum (SR) and stratum oriens (SO) of CA1 express netrin-G2. C, Quantitative analyses of immunofluorescence for netrin-G1 and netrin-G2 in the (Figure legend continues.) 
primer pair: 5' -AGGATCCGGAAGCGGAGCTACTAACTTCAGCCTG CTGAAGCAGGCTGGAGACGTGGAGGAGAACCCTGGACCTATGA GCGAGCTGATCA-3'/5' -AGAATTCTCATCTGTGCCCCAGTTTGC$3^{\prime}$. The pAAV-Cre-RFP ( $\mathrm{pK} 166$ ) was generated by ligation of Cre and P2A-RFP into the SalI/BamHI and BamHI/EcoRI sites of the pAAVEF1 $\alpha$-DIO EYFP vector (Addgene, 27056).

Constructs for overexpression experiments. The $\alpha 1$-chimaerin (WT), $\alpha 2$ chimaerin (WT), and $\alpha 2$-chimaerin $(\Delta \mathrm{N})$ cDNAs were described previously (Iwasato et al., 2007). The GAP-inactive $\alpha$-chimaerin mutant cDNAs $[\alpha 1$ chimaerin (R304G), $\alpha 2$-chimaerin (R304G), and $\alpha 2$-chimaerin ( $\Delta \mathrm{N}$ and R304G)] were generated by a PCR-based method using the following primer pair: 5'-GACTCTACGGAGTGTCAGGATTTAGTG-3'/5'-GACACTCCG TAGAGTCCTTCAGAATT- $3^{\prime}$. These six types of $\alpha$-chimaerin cDNAs were fused with the TagRFP (Evrogen) and inserted into the pCAG-loxPSTOP-loxP-pA vector (Niwa et al., 1991; Mizuno et al., 2014) to generate the pCAG-loxP-STOP-loxP- $\alpha 1$-chimaerin(WT)TagRFPpA (pK194), pCAG-loxP-STOP-loxP- $\alpha 1$-chimaerin(R304G)TagRFPpA (pK195), pCAG-loxP-STOP-loxP- $\alpha 2$-chimaerin(WT)TagRFP-pA (pK192), pCAG-loxP-STOP-loxP- $\alpha 2$-chimaerin(R304G)TagRFP-pA (pK193), pCAG-loxP-STOP-loxP- $\alpha 2$-chimaerin $(\Delta \mathrm{N})$ TagRFP-pA (pK196), and pCAG-loxP-STOP-loxP- $\alpha 2$-chimaerin $(\Delta \mathrm{N}$ and R304G)TagRFP$\mathrm{pA}$ (pK197) vectors. All coding sequences in each construct were verified by nucleotide sequencing. The primers and vectors are listed in Tables 1 and 2 , respectively.

\section{Histology}

For histological analyses, mice were overdosed with an intraperitoneal injection of pentobarbital. Mice for immunohistochemistry were transcardially perfused with saline. The brains from perfused mice were dissected and postfixed in $4 \%$ paraformaldehyde (PFA) in $0.1 \mathrm{~m}$ phosphate buffer (PB). For slice preparation, microslicer (Dosaka Zero 1) or cryostat (Leica CM 3050S) was used. Laminar structures and the $\alpha 2$ chimaerin protein expression pattern in the hippocampus were examined with coronal sections (100 and $60 \mu \mathrm{m}$, respectively). For axonal labeling, anti-netrin-G1 polyclonal antibody ( $\mathrm{pAb})$ and antinetrin-G2 pAb were used as described (Nishimura-Akiyoshi et al., 2007). Immunohistochemistry were performed with male mice that were $0-10$ months of age. For $\alpha 2$-chimaerin protein detection, anti- $\alpha 2$-chimaerin pAb (1:20,000) was used as described previously (Iwata et al., 2014).

\section{Golgi-Cox staining and analysis of dendrites}

Golgi-Cox staining was performed as described previously (Datwani et al., 2002; Iwasato et al., 2008). It was performed with adult male mice 6-7 months of age. Serial coronal sections $(100 \mu \mathrm{m})$ were cut using a microslicer (Dosaka Zero 1).

\section{$\leftarrow$}

(Figure legend continued.) hippocampus CA1 showed no significant differences between DT$\alpha 2 \mathrm{~K} 0$ and control mice. Netrin-G1 intensity was higher at SLM than at SR in both DT- $\alpha 2 \mathrm{~K} 0$ and control mice (control SR vs DT- $\alpha 2$ KO SR, $p=0.31$; control SLM vs DT- $\alpha 2$ KO SLM, $p=0.77$; control SR vs SLM, two-tailed paired Student's $t$ test, ${ }^{* * *} p<0.001$; DT- $\alpha 2$ KO SR vs SLM, two-tailed paired Student's $t$ test, $\left.{ }^{* * *} p<0.001\right)$. Netrin-G2 intensity was higher at SR than at SLM in both DT- $\alpha 2$ KO and control mice (control SR vs DT- $\alpha 2 \mathrm{KO}$ SR, $p=0.74$; control SLM vs DT- $\alpha 2$ KO SLM, $p=0.69$; control SR vs SLM, two-tailed paired Student's $t$ test, ${ }^{* * *} p<0.001$; DT- $\alpha 2$ KOSR vs SLM, two-tailed paired Student's ttest, $\left.{ }^{* * *} p<0.001\right)$. Control: eight slices, two mice; DT- $\alpha 2$ KO: six slices, two mice). D, AAV-RFP (Fig. 7A) was unilaterally injected into the $\mathrm{CA} 3$ region in adulthood. RFP-labeled $\mathrm{C} 33$ neurons projected to both ipsilateral and contralateral $\mathrm{CA} 1$ and $\mathrm{CA} 3$ regions in DT- $\alpha 2 \mathrm{~K} 0$ mice as in control mice. These results were also similar to normal projection patterns previously reported (Ishizuka et al., 1990; Naber et al., 2001). Control: two mice; DT- $\alpha 2 \mathrm{KO}$ : two mice. $E$, AAV-RFP was unilaterally injected into the CA1 region in adulthood. RFP-labeled CA1 neurons projected to the subiculum and layer V/VI entorhinal cortex in DT- $\alpha 2 \mathrm{KO}$ mice as in control mice. These results were also similar to normal projection patterns previously reported (Ishizuka et al., 1990; Naber et al., 2001). Control: two mice; DT$\alpha 2$ KO: two mice). $\boldsymbol{F}$, Left, Representative traces of Golgi-Cox-stained neurons from CA1 region of the hippocampus. Middle, Scholl analysis of CA1 pyramidal neurons in DT- $\alpha 2 \mathrm{KO}$ and control mice showed no significant differences in branch complexity throughout the dendritic trees (two-way ANOVA; $F_{(1,30)}=0.19, p=0.67$ for genotype). Right, Summed dendrite length was not significantly different between genotypes (primary apical, $p=0.41$; secondary apical, $p=$ 0.97; primary basal, $p=0.61$; secondary basal, $p=0.95$ ). Control: 16 dendrites, 5 mice; DT- $\alpha 2$ K0: 16 dendrites, 5 mice. Data are shown as mean \pm SEM.
Hippocampal CA1 pyramidal neurons whose cell bodies were located at the midlevels of each section and whose dendrites were isolated from those of neighboring neurons were randomly selected from the dorsal region of hippocampus under a light microscope with a $20 \times$ objective. Images of adjacent focal planes were stacked and analyzed using ImageJ. Dendrite length and number of dendritic branches were analyzed after importing stacked images into Imaris Filament Tracer software (Bitplane) and tracing neurons. Dendrite branching was studied by Scholl analysis. In brief, a series of concentric rings spaced $20 \mu \mathrm{m}$ apart were laid over the soma center and Scholl measurements were obtained by counting the number of dendrites that crossed each $20 \mu \mathrm{m}$ ring (Fig. $1 F$ ).

\section{In utero electroporation}

In utero electroporation (IUE) was performed as previously described (Mizuno et al., 2014) with some modification. In brief, pregnant mice at embryonic day (E) 14.5 were anesthetized with sodium pentobarbital (50 $\mathrm{mg} \mathrm{kg}^{-1}$, i.p.) in saline. A midline laparotomy was performed to expose the uterus. For DNA microinjection, glass capillary tubes (Harvard Apparatus) were pulled using a micropipette puller (Narishige). A total of $0.5 \mu \mathrm{l}$ of DNA solution was injected into the lateral ventricle of embryos, and square electric pulses $(40 \mathrm{~V}, 50 \mathrm{~ms})$ were delivered five times at $1 \mathrm{~Hz}$ by an electroporator (NepaGene). After electroporation, the uterus was repositioned and the abdominal wall and skin were sutured.

\section{Supernova system}

To label neurons sparsely and brightly, we used the Supernova RFP system, which we reported recently (Mizuno et al., 2014). The Supernova system takes advantage of the feature of tetracycline response element (TRE) and tetracycline transactivator (tTA) that, in the absence of the tTA, the TRE occasionally drives gene expression, albeit very weakly. The Supernova RFP system used in the present study consists of TRE-FlpeWPRE-pA (vector 1: pK036) and CAG-FRT-STOP-FRT-TurboRFPires-tTA-WPRE-pA (vector 2: pK037; Figs. 2B, 4, 5), or TRE-Cre-pA (vector 1: pK031) and CAG-loxP-STOP-loxP-TurboRFP-ires-tTAWPRE-pA (vector 2: pK029; Fig. 3D). In cells carrying both vectors 1 and 2, leakage from TRE drives weak expression of Flpe or Cre on rare occasions. Subsequently, only in these cells, Flpe-mediated or Cre-mediated recombination removes the FRT-STOP-FRT cassette or loxP-STOPloxP cassette from vector 2 , and both $\mathrm{tTA}$ and RFP are expressed from the CAG promoter. The expression of tTA facilitates the positive feedback of the tTA/TRE cycles, and leads to the strong expression of RFP only in the sparse population of transfected cells. These vectors, delivered to hippocampal CA1 pyramidal neurons by IUE at E14.5, were used in Figures $2 B$ and $3-5$.

\section{Supernova overexpression experiments}

To overexpress a gene of interest (gene X) in sparse neurons, we used the Supernova overexpression method. This system consists of TRE-Cre-pA (vector 1: pK031), CAG-loxP-STOP-loxP-TurboRFP/AmCyan-irestTA-WPRE-pA (vector 2: pK029/pK039), and CAG-loxP-STOP-loxP(gene $\mathrm{X}$ )-pA (vector 3). These vectors were delivered to hippocampal CA1 pyramidal neurons by IUE at E14.5. For control, the following groups and mixtures were used: groups: $\alpha 2(\mathrm{WT}) \mathrm{OE}, \alpha 2(\mathrm{R} 304 \mathrm{G}) \mathrm{OE}$, $\alpha 2(\Delta \mathrm{N}) \mathrm{OE}, \alpha 2(\Delta \mathrm{N}$ and R304G)OE, $\alpha 1(\mathrm{WT}) \mathrm{OE}$, and $\alpha 1(\mathrm{R} 304 \mathrm{G}) \mathrm{OE}$ (Fig. 3); mixtures: pCAG-loxP-STOP-loxP-TurboRFP/AmCyan-irestTA-WPRE-pA (pK029/pK039: $\left.1 \mu \mathrm{g} \mu \mathrm{l}^{-1}\right)$ and pTRE-nlsCre-pA ( pK031:20-50 ng $\mu \mathrm{l}^{-1}$ ); pK029/pK039, pK031, and pK192 $\left(1 \mu \mathrm{g} \mu \mathrm{l}^{-1}\right.$ ); pK029/pK039, pK031, and pK193 (1 $\left.\mu \mathrm{g} \mu \mathrm{l}^{-1}\right)$; pK029/pK039, pK031, and pK194 $\left(1 \mu \mathrm{g} \mu \mathrm{l}^{-1}\right)$; pK029, pK031, and $\mathrm{pK} 195\left(1 \mu \mathrm{g} \mu \mathrm{l}^{-1}\right)$; pK029/ pK039, pK031, and pK196 $\left(1 \mu \mathrm{g} \mu \mathrm{l}^{-1}\right)$; and pK029, pK031, and pK197 $\left.\left(1 \mu \mathrm{g} \mu \mathrm{l}^{-1}\right)\right]$, respectively.

Quantitative analyses (blind test) of Supernova overexpression experiments (Fig. $3 B$ ) were conducted carefully as follows: an experimenter, Experimenter 1, prepared vector mixtures for another experimenter, Experimenter 2, without informing Experimenter 2 of the contents of mixtures. Experimenter 2 transfected hippocampal pyramidal neurons of progeny of B6 males and ICR females with a mixtures by IUE. Experimenter 1 anesthetized these mice at the juvenile stage [at postnatal day (P) 22-P23] with tribromoethanol $\left(125 \mathrm{mg} \mathrm{kg}^{-1}\right.$, i.p.) and perfused them transcardially with $0.9 \% \mathrm{NaCl}$ and $4 \%$ PFA in $0.1 \mathrm{M} \mathrm{PB}$. Experi- 
A
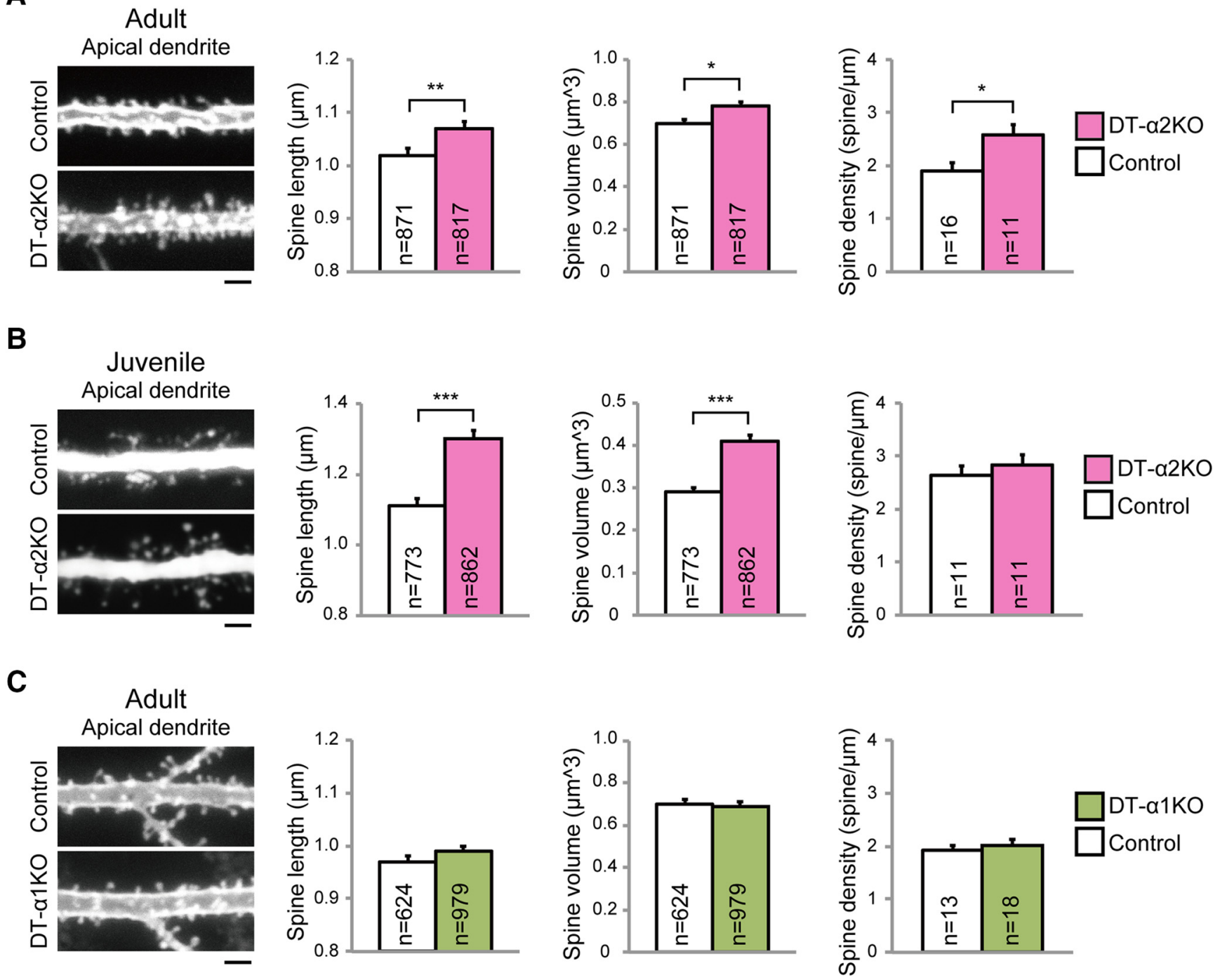

Figure 2. $\quad \alpha 2$-Chimaerin regulates the size and density of hippocampal dendritic spines. $\boldsymbol{A}$, Representative images of apical dendrites of hippocampal CA1 neurons from DT- $\alpha 2 \mathrm{~K} 0$ mice and their control mice in adulthood. In adulthood, DT- $\alpha 2$ KO mice showed significantly increased dendritic spine length and volume compared with the control mice (spine length, ${ }^{* *} p<0.01 ;$ spine volume, $\left.{ }^{*} p<0.05\right)$. The dendritic spine density was also increased in DT- $\alpha 2 \mathrm{KO}$ mice compared with the control mice ( ${ }^{*} p<0.05$; control: 871 spines, 16 dendrites, 6 mice; DT- $\alpha 2 \mathrm{~K} 0: 817$ spines, 11 dendrites, 6 mice). (A1 neurons were sparsely labeled by Dil. $B$, Representative images of apical dendrites of hippocampal CA1 neurons from DT- $\alpha 2$ K0 mice and those from control mice at P24. In the juvenile stage (at P24), DT- $\alpha 2$ KO mice showed significantly increased dendritic spine length and volume compared with the control mice (spine length, ${ }^{* * *} p<0.001 ;$ spine volume, ${ }^{* * *} p<$ 0.001). Meanwhile, spine density was unaltered between genotypes ( $p=0.49$; control: 773 spines, 11 dendrites, 7 mice; DT- $\alpha 2$ K0: 862 spines, 11 dendrites, 6 mice). Spines of juvenile mice were labeled by the IUE-based Supernova method (Mizuno et al., 2014), which is a powerful approach to brightly label individual neurons in the brains of young animals. C, Representative images of apical dendrites of hippocampal CA1 neurons from DT- $\alpha 1 \mathrm{~K} 0$ mice and their control mice in adulthood. DT- $\alpha 1 \mathrm{~K} 0$ mice showed normal spine morphology and density. There were no significant difference between DT- $\alpha 1 \mathrm{~K} 0$ and their control mice (spine length, $p=0.78$; spine volume, $p=0.54$; spine density, $p=0.54$ ). Control: 624 spines, 13 dendrites, 5 mice; DT- $\alpha 1 \mathrm{KO}$ : 979 spines, 18 dendrites, 11 mice. Spine length and spine volume: Mann-Whitney $U$ test. Spine density: two-tailed unpaired Student's $t$ test. Data are shown as mean \pm SEM. Scale bars, $2 \mu m$. CA1 neurons were sparsely labeled by Dil.

menter 1 intermingled brains from control, $\alpha 2(\mathrm{WT}) \mathrm{OE}$, and $\alpha 2$ (R304G)OE groups, and handed these brains to Experimenter 2 without attaching the information about the groups. Experimenter 2 conducted all subsequent experiments and analyses. Brains were trimmed and cut by a microslicer (Dosaka) into $150-\mu \mathrm{m}$-thick coronal slices. Each slice was mounted on a glass slide and covered with Vectashield mounting media (Vector Laboratories) containing 4',6'-diamidino-2phenylindole (DAPI) for nuclear staining. The information about groups was disclosed to Experimenter 2 only after all experiments and analyses were completed.

\section{Spine labeling}

To analyze spine morphologies, sparse and bright labeling of neurons is necessary. Spines of juvenile mice were labeled by the IUE-based Supernova method (Mizuno et al., 2014), which is a powerful approach to brightly label individual neurons in the brains of young animals. For images of Figures $2 B, 4$, and 5, Flpe/FRT-based Supernova vector sets [pK037 $\left(1 \mu \mathrm{g} \mu \mathrm{l}^{-1}\right)$ and pK036 (50 ng $\left.\mu \mathrm{l}^{-1}\right)$ ] were introduced into the hippocampal pyramidal neurons by IUE. Mice were anesthetized with tribromoethanol $\left(125 \mathrm{mg} \mathrm{kg}^{-1}\right.$, i.p.), and perfused transcardially with $0.9 \% \mathrm{NaCl}$ and $4 \%$ PFA in $0.1 \mathrm{M} \mathrm{PB}$. Brains were trimmed and cut by a microslicer (Dosaka) into $150-\mu \mathrm{m}$-thick coronal slices. Each slice was mounted on a glass slide and covered with Vectashield mounting media (Vector Laboratories) containing DAPI for nuclear staining.

Spines of P61-P81 (Fig. 2A), P64-P92 (Fig. 2C), and P73-P79 (Fig. 6) mice were visualized by DiI labeling. Mice were anesthetized with tribromoethanol (125 $\mathrm{mg} \mathrm{kg}^{-1}$, i.p.), and perfused transcardially with $0.9 \%$ $\mathrm{NaCl}$ and $4 \%$ PFA in $0.1 \mathrm{M} \mathrm{PB}$. Brains were trimmed and cut by a microslicer (Dosaka) into $150-\mu \mathrm{m}$-thick coronal slices. Lipophilic dye (DiI, 
A

a2-chimaerin (WT)

a2-chimaerin (R304G)
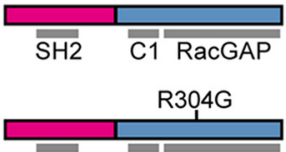

a2-chimaerin $(\Delta \mathrm{N})$

a2-chimaerin ( $\triangle N / R 304 G)$

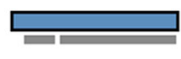

R304G a1-chimaerin (WT)

a1-chimaerin (R304G)
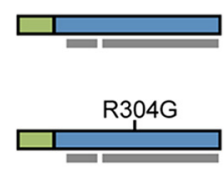

50 aa

1 -specific $\mathrm{N}$ terminus

2-specific $\mathrm{N}$ terminus

a1,2-common $\mathrm{C}$ terminus

B
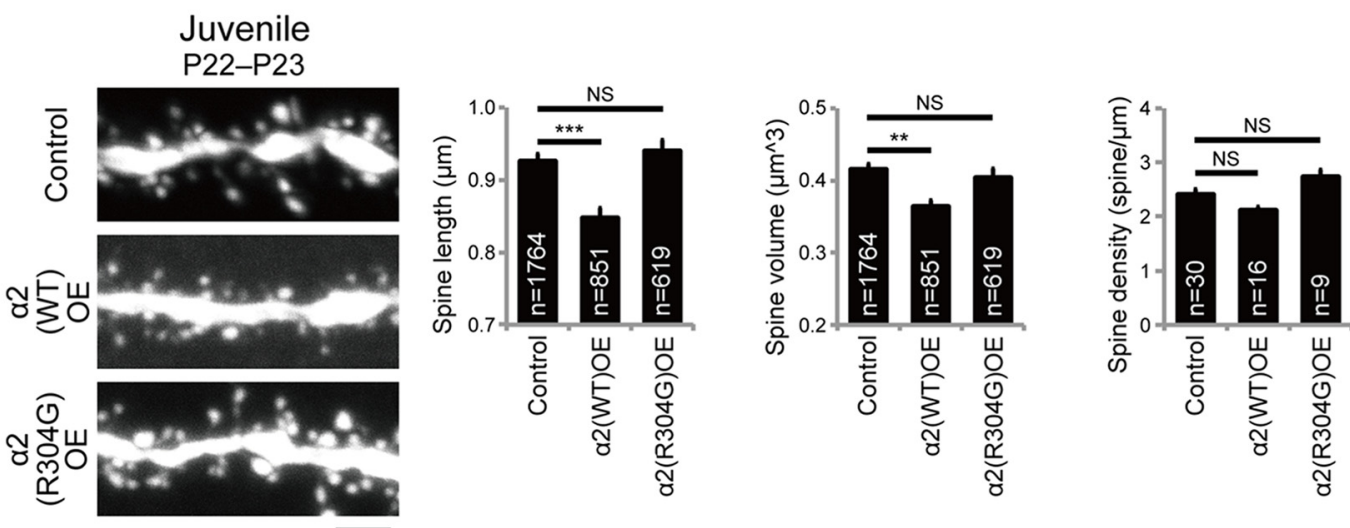

C

Control

a2-chimaerin

a2-chimaerin

a2-chimaerin

a2-chimaerin

a1-chimaerin

a1-chimaerin
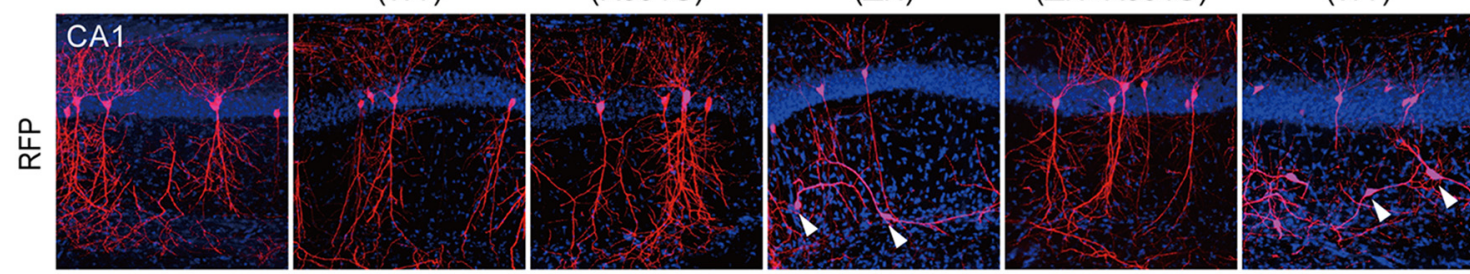

(R304G)

D

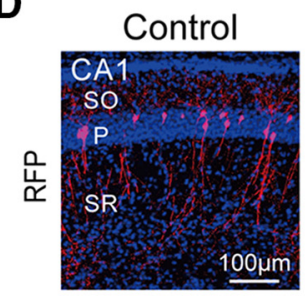

$\mathbf{F}$

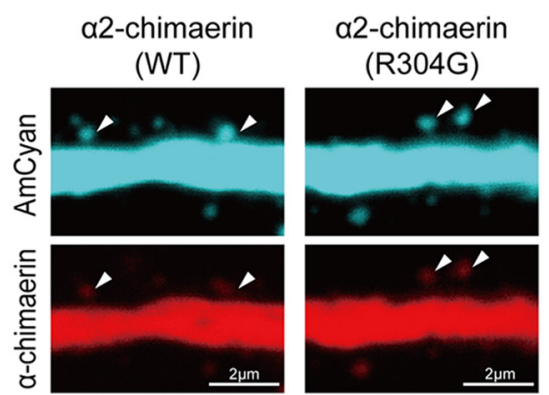

E
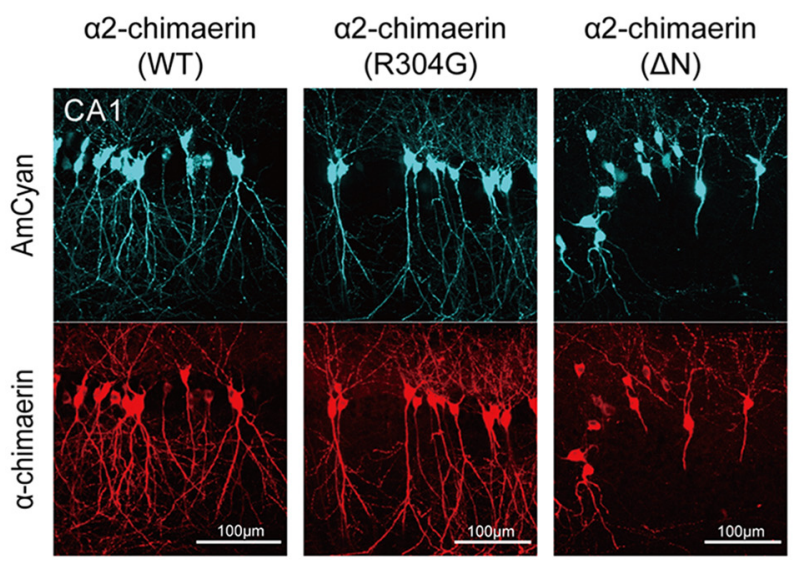

a1-chimaerin

(WT)

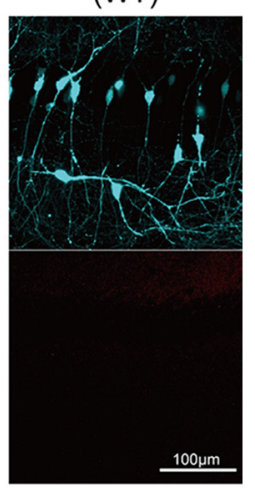

Figure 3. $\quad \alpha 2$-Chimaerin negatively regulates spine size in a RacGAP activity-dependent manner. $\boldsymbol{A}$, Schematics of WT $\alpha 1$-chimaerin $[\alpha 1$-chimaerin (WT)] and $\alpha 2$-chimaerin (WT) and their mutants. Both the $\alpha 1$-chimaerin and $\alpha 2$-chimaerin contain $\mathrm{C} 1$ and RacGAP domains in their C termini. $\alpha 2$-Chimaerin has an SH2 domain in its $\mathrm{N}$ terminus, whereas $\alpha 1$-chimaerin has a relatively short $\mathrm{N}$ terminus that does not contain any recognizable domains. $\alpha 2$-Chimaerin-specific $\mathrm{N}$ terminus is deleted in $\alpha 2$-chimaerin $(\Delta \mathrm{N})$. $\alpha 1$-Chimaerin (R304G) and $\alpha 2$-chimaerin (R304G) are RacGAP-inactive mutants. $\alpha 2$-Chimaerin ( $\Delta \mathrm{N}$ and R304G) lost both $\mathrm{N}$ terminus and RacGAP activity. Each of these proteins was fused to a monomeric RFP in the (Figure legend continues.) 
Invitrogen, Life Technologies) was coated onto tungsten, according to previous reports (Mataga et al., 2004). DiI-coated particles were delivered to the slices using Helios Gene Gun (Bio-rad) system. A polycarbonate filter with a $3.0 \mu \mathrm{m}$ pore size (BD Biosciences) was inserted between the gun and the preparation. The DiI was allowed to transport for $24 \mathrm{~h}$ in fixative before imaging. Each slice was mounted on coverslips in Vectashield mounting media (Vector Laboratories) containing DAPI for nuclear staining.

\section{Image analysis and quantification of dendritic spines}

Images of dendritic spines in primary apical (Figs. 2, 5, 6), oblique (Fig. 3), or basal dendrites of pyramidal neurons in the CA1 region of hippocampus were taken on a Leica TSC-SP5 confocal microscope. Sequential $z$-images consisted of optical sections $(1024 \times 1024$ pixels $)$ with $0.1 \mu \mathrm{m}$ intervals using a $63 \times$ oil immersion objective (numerical aperture, 1.3) with $9 \times$ zoom. The $z$-images were $3 \mathrm{D}$ reconstructed and some parameters (spine length, spine maximum width, spine mean width, spine minimum width, spine area, spine volume, and density) were measured by the Imaris Filament Tracer software (Bitplane).

Virus preparation

The AAV (adeno-associated virus) vector was prepared using AAV-DJ/8 Helper Free Packaging System (Cell Biolabs). The recombinant AAV was generated by lipofection (293fectin, Life Technologies) of pAAV. RC (Agilent Technologies, 240071), pHelper (Agilent Technologies,

(Figure legend continued.) C-terminal regions and was sparsely expressed in the hippocampal neurons using the Supernova overexpression method. $\boldsymbol{B}$, Left, Representative RFP images of oblique dendrites of hippocampal CA1 neurons at P22-P23, in which $\alpha 2$-chimaerin [WT; $\alpha 2$ (WT)0E], $\alpha 2$-chimaerin [R304G; $\alpha 2$ (R304G)0E], or no $\alpha 2$-chimaerin (control) was overexpressed together with RFP. Right, $\alpha 2$ (WT)OE neurons, but not $\alpha 2$ (R304G)0E neurons, showed decreased spine length and volume compared with the control neurons (spine length: KruskalWallis H test, ${ }^{* * *} p<0.001$; Mann-Whitney U test with a Bonferroni's correction; WT, ${ }^{* * *} p<$ 0.001 ; R304G, $p=0.63$ vs control, respectively; spine volume: Kruskal-Wallis $H$ test, ${ }^{* *} p<0.01$; Mann-Whitney Utest with a Bonferroni's correction; WT, ${ }^{* *} p<0.01 ; \mathrm{R} 304 \mathrm{G}, p=$ 1.00 vs control, respectively). The spine densities of $\alpha 2$ (WT)OE and $\alpha 2$ (R304G) 0 E neurons were not significantly different from those of control neurons (one-way ANOVA: $F_{(2,52)}=4.13,{ }^{*} p<$ 0.05 for genotype, two-tailed unpaired Student's $t$ test with Bonferroni's correction; WT, $p=$ 0.25 ; R304G, $p=0.30$ vs control, respectively). Control: 1764 spines, 30 dendrites, 13 mice; $\alpha 2$ (WT)0E: 851 spines, 16 dendrites, 4 mice; $\alpha 2$ (R304G)0E: 619 spines, 9 dendrites, 6 mice. C, CA1 pyramidal neurons from juvenile mice (at P22-P23), in which $\alpha 1$-chimaerin, $\alpha 2$ chimaerin, or one of their mutants was overexpressed together with RFP by the IUE-based Supernova overexpression method. In control neurons, only vectors 1 and 2 (see Materials and Methods) were introduced. Overexpression of either $\alpha 1$-chimaerin or $\alpha 2$-chimaerin $(\Delta \mathrm{N})$ in the CA1 neurons affected cell localization and dendritic morphology (arrowheads). These abnormalities were not observed in RacGAP-inactive mutant R304G-expressing neurons [ $\alpha 2$ chimaerin ( $\Delta \mathrm{N}$ and $\mathrm{R} 304 \mathrm{G}), \alpha 1$-chimaerin (R304G)], suggesting that the abnormal cell positioning and shapes require RacGAP activity. In contrast, neurons overexpressing $\alpha 2$ chimaerin (WT) or RacGAP-inactive $\alpha 2$-chimaerin (R304G) were normally located in the pyramidal layer of CA1. These results are consistent with the view that the $\alpha 2$-chimaerin-specific N terminus has an autoinhibitory function that blocks RacGAP activity when the molecule needs to be inactive (Canagarajah et al., 2004; Colón-González et al., 2008). Blue color indicated DAPI signal. $\boldsymbol{D}, \alpha 2 \mathrm{~K} 0$ mice showed normal position of CA1 neurons at P14 [number of cells in CA1 pyramidal layer/number of RFP labeling cells $=617 / 627$ (control), $718 / 726(\alpha 2 \mathrm{KO})$ ), suggesting overtly normal cell migration. Control: three mice; $\alpha 2 \mathrm{KO}$ : three mice. P, Pyramidal layer. $\boldsymbol{E}$, CA1 pyramidal neurons from juvenile mice (at P22), in which $\alpha 2$-chimaerin (WT), $\alpha 2$ chimaerin (R304G), $\alpha 2$-chimaerin $(\Delta \mathrm{N})$, or $\alpha 1$-chimaerin (WT) was overexpressed together with AmCyan using the IUE-based Supernova overexpression method. Cellular morphology and positioning was visualized by AmCyan and subcellular localization patterns of $\alpha 2$-chimaerin (WT/R304G/ $\Delta \mathrm{N}$ ) and $\alpha 1$-chimaerin (WT) were visualized by RFP fused to the molecules. Subcellular localization patterns of $\alpha 2$-chimaerin ( $\Delta \mathrm{N}$ and R304G) were similar to those of $\alpha 2$ chimaerin (WT). $\alpha 1$-Chimaerin (WT) was not detected, possibly because $\alpha 1$-chimaerin was rapidly removed by degradation signals on the $\alpha 1$-chimaerin-specific $\mathrm{N}$ terminus, as suggested by a previous in vitro study (Marland et al., 2011). $\boldsymbol{F}$, Representative images of RFP-fused $\alpha 2$ chimaerin (WT/R304G) and AmCyan expressing apical dendrites of hippocampal CA1 neurons from juvenile mice (at P22). RFP signals were detected in spines (arrowheads) from RFP-fused $\alpha 2$-chimaerin (WT/R304G)-expressing neurons. Data are shown as mean \pm SEM. Scale bars: $\boldsymbol{B}$, $F, 2 \mu \mathrm{m} ;(-E, 100 \mu \mathrm{m}$.
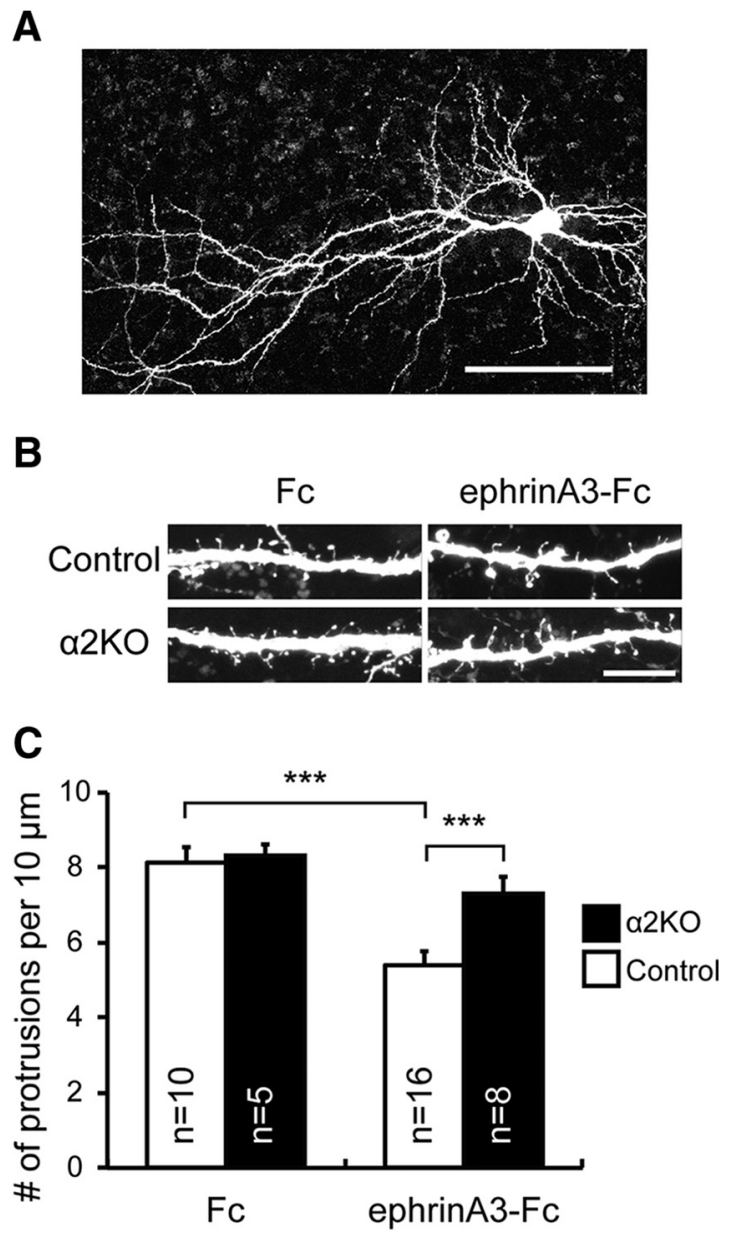

Figure 4. EphrinA3-induced spine retraction in hippocampal neurons is suppressed by lack of $\alpha 2$-chimaerin. $\boldsymbol{A}, \mathrm{A}$ sparsely labeled RFP-expressing cell (by IUE-based Supernova RFP method) with typical morphology of hippocampal pyramidal neurons in organotypic hippocampal slices (sixth day in vitro) prepared from P5 mice. $\boldsymbol{B}$, Segments of dendrites from hippocampal slices from $\alpha 2 \mathrm{KO}$ and control mice, after treatment with ephrinA3-Fc or Fc (negative control). $C$, The spine density was decreased by ephrinA3-Fc treatment in neurons derived from control mice $\left({ }^{* * *} p<0.001\right)$, but not in those from $\alpha 2 \mathrm{KO}$ mice $(p=0.13)$. There was no change with $\mathrm{Fc}$ treatments between genotypes $(p=0.79)$. Thus ephrinA3-Fc-induced spine retraction was suppressed in $\alpha 2 K 0$ neurons ( ${ }^{* *} p<0.001$ ). Spine size (length and volume) was not analyzed because this organ culture system is suitable for the analyses of the effects of EphA signaling to the spine density but not to the spine size (Fu et al., 2007). Control Fc: 10 dendrites, 6 mice; $\alpha 2$ KO Fc: 5 dendrites, 3 mice; control EphrinA3-Fc: 16 dendrites, 10 mice; $\alpha 2$ KO EphrinA3-Fc: 8 dendrites, 4 mice. Two-tailed unpaired Student's $t$ test. Data are shown as mean \pm SEM. Scale bars: $\boldsymbol{A}, 100 \mu \mathrm{m} ; \boldsymbol{B}, 10 \mu \mathrm{m}$.

240071), and pAAV shuttle vector into HEK293FT cells in complete medium (DMEM containing 10\% heat-inactivated FBS, $1 \mathrm{~mm}$ sodium pyruvate solution, $0.075 \%$ sodium bicarbonate solution) with penicillin and streptomycin. At $72 \mathrm{~h}$ after transfection, cells were harvested and centrifuged at $2500 \mathrm{rpm}$ for $30 \mathrm{~min}$, and the supernatant was passed through a $0.45 \mu \mathrm{m}$ membrane filter (Millipore). The filtered supernatant was transferred to ultracentrifuge tubes and $20 \%$ sucrose/PBS was added. The supernatant was centrifuged at $22,000 \mathrm{rpm}$ at $4^{\circ} \mathrm{C}$ for $2 \mathrm{~h}$. The virus pellet was resuspended in $\mathrm{PBS}$ and stored at $-80^{\circ} \mathrm{C}$. The genomic titer of each virus was determined by quantitative PCR using the following primer pair: 5'-GAGTTTCCCCACACTGAGTG-3' $/ 5^{\prime}$-GAGGCTTGA GAATGAACCAAGA-3'. The primers are listed in Table 1.

\section{Virus injection}

Focal injection within the CA3 and CA1 regions of hippocampus. Axon labeling was performed with adult mice 6-14 months of age. Mice were anesthetized with $1.5-3 \%$ isoflurane and placed into a stereotaxic frame 
A

Experimental design

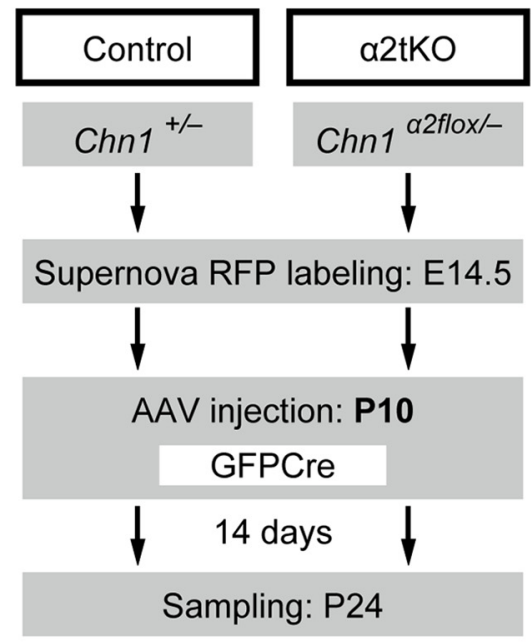

\section{AAV-GFPCre}

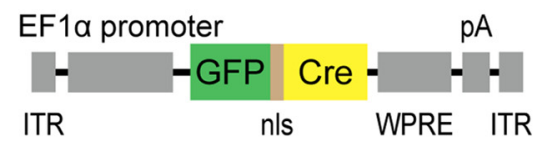

B

Hippocampus (P24)

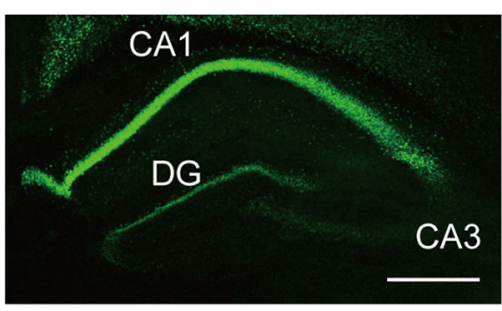

GFPCre
C

CA1 (P24)

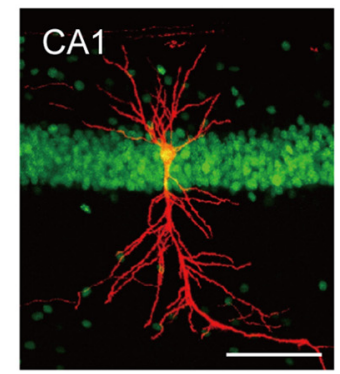

GFPCre

RFP
Contra- AAV-

lateral GFPCre

E
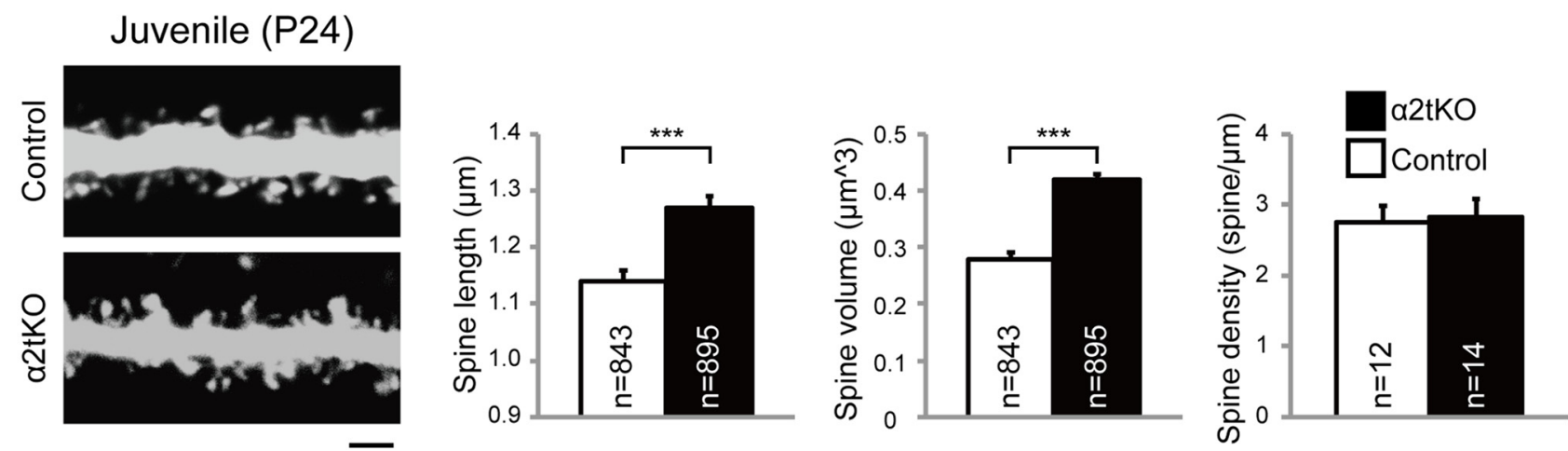

Figure 5. Dendritic spine morphology is affected by late postnatal $\alpha 2$-chimaerin function. $\boldsymbol{A}$, Schematic depicting the experimental design. $\boldsymbol{B}$, Typical GFPCre expression pattern in the juvenile hippocampus at $14 \mathrm{~d}$ postinfection. The AAV-GFPCre vector was injected into the CA1 region at P10 and samples were prepared at P24. C, Typical morphology of a GFPCre-positive hippocampal CA1 pyramidal neuron sparsely labeled by the Supernova RFP method. $\boldsymbol{D}$, Western blot analysis of the juvenile hippocampus (at P24) using anti- $\alpha 2$-chimaerin antibody. Expression of $\alpha 2$-chimaerin was significantly lower in the AAV-GFPCre-injected hippocampus than in the contralateral side (one-tailed paired Student's t test, ${ }^{*} p<0.05$; contralateral: 1.00 $\pm 0.10 ;$ AAV-GFPCre: $0.49 \pm 0.08 ; 4$ mice each). Most of the remaining $\alpha 2$-chimaerin expression in AAV-injected side was likely from the DG and CA3 regions, where GFPCre expression was low (Fig. 5B). $\boldsymbol{E}$, Representative images of Supernova RFP-labeled apical dendrites of hippocampal CA1 $\alpha 2$ tKO neurons and their control neurons in the juvenile stage (at P24). $\alpha 2$ tKO neurons showed significantly increased dendritic spine length and volume compared with control neurons (spine length, ${ }^{* * *} p<0.001$; spine volume, $\left.{ }^{* * *} p<0.001\right)$. Meanwhile, spine density was unaltered between genotypes $(p=0.84)$. Control: 843 spines, 12 dendrites, 4 mice; $\alpha 2$ tK0: 895 spines, 14 dendrites, 5 mice. Spine length and spine volume: Mann-Whitney U test. Spine density: two-tailed unpaired Student's $t$ test. Data are shown as mean \pm SEM. Scale bars: $\boldsymbol{B}, 500 \mu \mathrm{m} ; \boldsymbol{C}, 100 \mu \mathrm{m} ; \boldsymbol{E}, 2 \mu \mathrm{m}$.

(Narishige). The skull was exposed surgically and drilled using a hand drill (Minimo). Forty nanoliters of AAV-RFP $\left(1.0 \times 10^{13}\right.$ viral genomes $\mathrm{ml}^{-1}$ ) was injected unilaterally into the right hippocampal CA1 (anterior-posterior: $-2.18 \mathrm{~mm}$; medial-lateral: $+1.5 \mathrm{~mm}$; dorsal-ventral: $-1.75 \mathrm{~mm}$ from the dural surface) and CA3 (anterior-posterior: -3.16 $\mathrm{mm}$; medial-lateral: $+3.25 \mathrm{~mm}$; dorsal-ventral: $-2.75 \mathrm{~mm}$ from the dural surface) regions (Fig. $1 D, E$ ). Virus delivery was performed at a rate of $20 \mathrm{nl} \mathrm{min}{ }^{-1}$ using a programmable syringe pump (KD Scientific) with 34 gauge beveled NanoFil needle (World Precision Instruments). Twenty days after injection, mice were killed and their brains were fixed and horizontally sectioned.
Hippocampal injection in juvenile mice. P10 mice were anesthetized with $1.0-2.0 \%$ isoflurane. The skull was exposed surgically and drilled using a hand drill (Minimo). For spine analysis (Fig. 5), $500 \mathrm{nl}$ of AAVGFPCre $\left(9.0 \times 10^{13}\right.$ viral genomes $\left.\mathrm{ml}^{-1}\right)$ was injected unilaterally into the right hippocampus (Figs. 5, 7). The injection site was located $\sim 1 \mathrm{~mm}$ lateral to the sagittal suture, halfway between the lambda and bregma, and $-1.5 \mathrm{~mm}$ from the dural surface. Virus delivery was performed at a

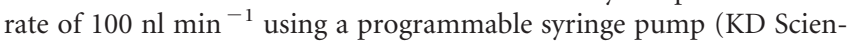
tific) with a 34 gauge beveled NanoFil needle (World Precision Instruments). For behavioral analysis (Fig. 7), $2000 \mathrm{nl}$ (total) of AAV-RFP $\left(7.0 \times 10^{13}\right.$ viral genomes $\left.\mathrm{ml}^{-1}\right)$ or AAV-Cre-RFP $\left(9.0 \times 10^{13}\right.$ viral 
A

\section{Experimental design}

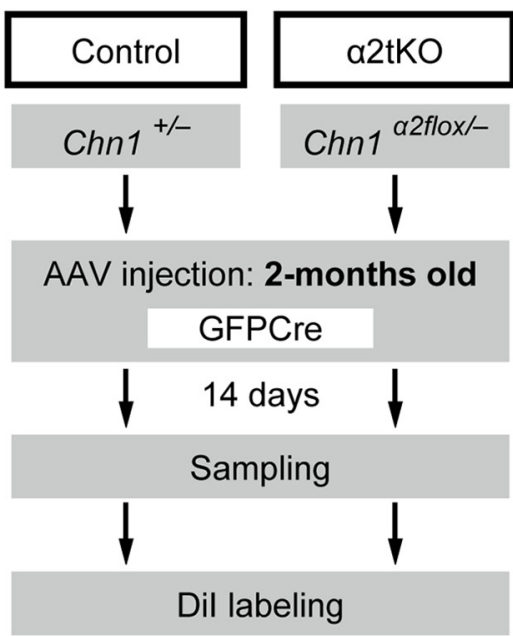

\section{AAV-GFPCre}

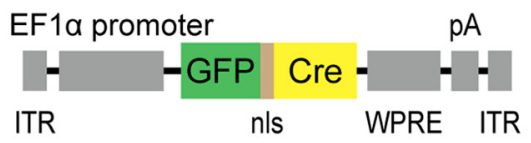

B

Hippocampus (Adult)

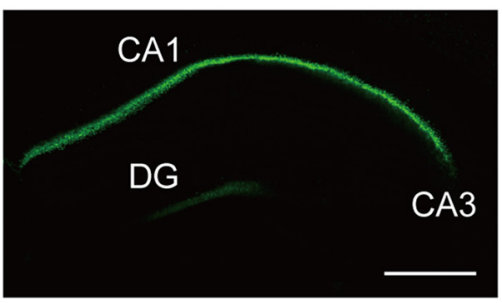

GFPCre
C

\section{CA1 (Adult)}

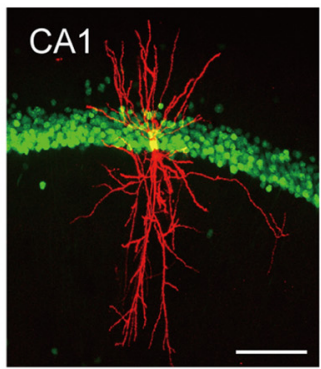

GFPCre

D
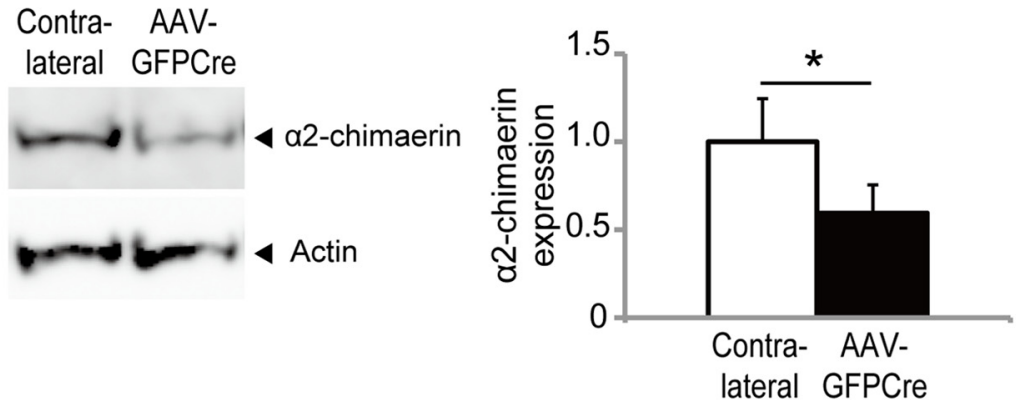

E
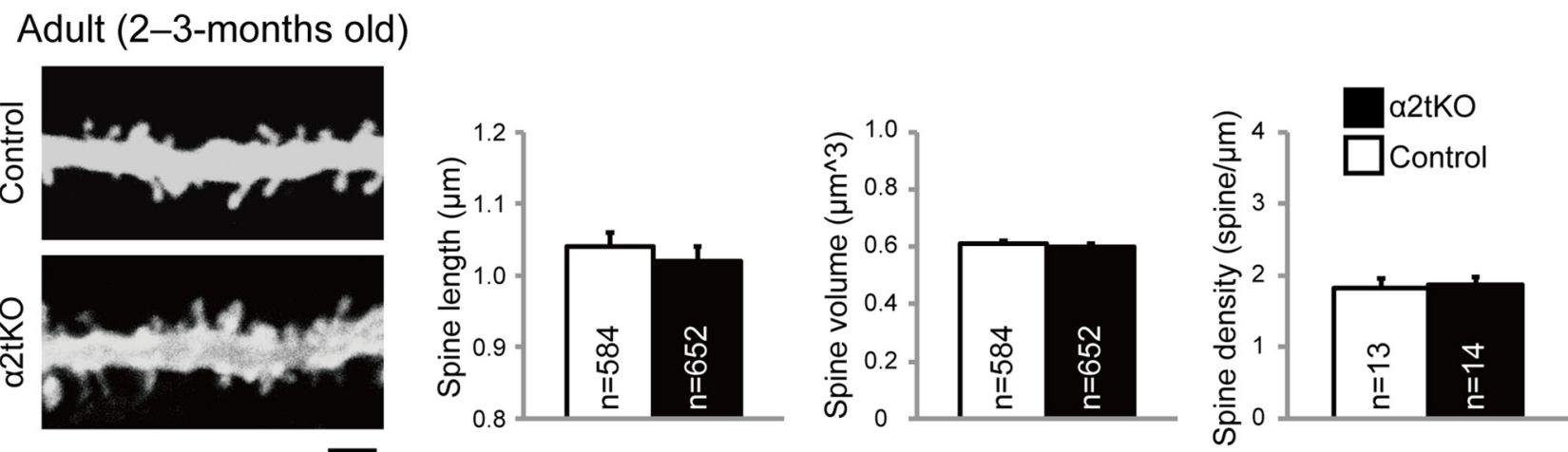

Figure 6. $\alpha 2$-Chimaerin function in adulthood is dispensable for dendritic spine morphogenesis. $\boldsymbol{A}$, Schematic depicting the experimental design. $\boldsymbol{B}$, Typical GFPCre expression pattern in the adult hippocampus at $14 \mathrm{~d}$ postinfection. The AAV-GFPCre vector was injected into the CA1 region at 2 months. C, Typical morphology of a Dil-labeled GFPCre-positive CA1 pyramidal neuron. $\boldsymbol{D}$, Western blot analysis of the adult hippocampus using anti- $\alpha 2$-chimaerin antibody. Expression of $\alpha 2$-chimaerin was significantly lower in the AAV-GFPCre-injected hippocampus than in contralateral side (one-tailed paired Student's $t$ test, ${ }^{*} p<0.05$; contralateral: $1.00 \pm 0.25$; AAV-GFPCre: $0.59 \pm 0.16 ; 4$ mice each). Most of the remaining of $\alpha 2$-chimaerin expression in AAV-injected side was likely from the DG and CA3 regions, where GFPCre expression was low (Fig. 6B). E, Representative images of Dil-labeled apical dendrites of hippocampal CA1 $\alpha 2$ tKO neurons and their control neurons in adulthood ( $2-3$ months old). $\alpha 2$-Chimaerin disruption in adulthood failed to alter the spine morphology and density in adulthood (spine length, $p=0.38$; spine volume, $p=0.63$; spine density, $p=0.76$ ). Control: 584 spines, 13 dendrites, 5 mice; $\alpha 2$ tkO: 652 spines, 14 dendrites, 5 mice. Spine length and spine volume: Mann-Whitney $U$ test. Spine density: two-tailed unpaired Student's $t$ test. Data are shown as mean \pm SEM. Scale bars: $\boldsymbol{B}, 500 \mu \mathrm{m} ; \boldsymbol{C}, 100 \mu \mathrm{m} ; \boldsymbol{E}, 2 \mu \mathrm{m}$.

genomes $\mathrm{ml}^{-1}$ ) was injected bilaterally into the hippocampus. The injection site was located $\sim 1 \mathrm{~mm}$ lateral to the sagittal suture, halfway between the lambda and bregma, and $-1.5 \mathrm{~mm}$ from the dural surface. Virus delivery was performed at a rate of $200 \mathrm{nl} \mathrm{min}^{-1}$ using a programmable syringe pump (KD Scientific) with a 34 gauge beveled NanoFil needle (World Precision Instruments). The blind tests for behavioral analyses were conducted in a manner similar to that described for the Supernova overexpression experiments.

Global injection in the hippocampus of adult mice. Male mice 2 months old were anesthetized with $1.5-3 \%$ isoflurane and placed into a stereotaxic frame (Narishige). The skull was exposed surgically and drilled using a hand drill (Minimo). Five hundred nanoliters of AAV-GFPCre $\left(9.0 \times 10^{13}\right.$ viral genomes $\left.\mathrm{ml}^{-1}\right)$ were injected unilaterally into the right dorsal hippocampus (anterior-posterior, $-2.0 \mathrm{~mm}$; medial-lateral, $+1.5 \mathrm{~mm}$; dorsal-ventral, $-1.5 \mathrm{~mm}$ from the dural surface; Fig. 6). Virus delivery was performed at a rate of $100 \mathrm{nl} \mathrm{min}{ }^{-1}$ using a programmable syringe pump (KD Scientific) with a 34 gauge beveled NanoFil needle (World Precision Instruments). Fourteen days after injection, mice were killed and their brains were fixed and coronally sectioned.

\section{Western blot analysis}

Western blot analyses were performed as previously reported (Iwata et al., 2014). AAV-GFPCre-injected $\alpha 2$-chimaerin-floxed (Chn1 ${ }^{\alpha 2 f l o x / \alpha 2 f l o x}$ ) mouse hippocampus (AAV-GFPCre-injected side and contralateral side) was homogenized in Pro-PREP protein extraction solution (iNtROM Biotechnology), and clarified by centrifugation. Proteins were separated by 
Table 2. Vector information

\begin{tabular}{|c|c|c|}
\hline Vector ID & Construct & Figure \\
\hline pK029 & pCAG-IoxP-stop-loxP-TurboRFP-ires-tTA-WPRE-pA & Fig. $3 B-D$ \\
\hline pK031 & pTRE-Cre-pA & Fig. 3B-F \\
\hline pK036 & pTRE-Flpe-WPRE-pA & Figs. $2 B, 4,5$ \\
\hline pK037 & pCAG-FRT-stop-FRT-TurboRFP-ires-tTA-WPRE-pA & Figs. $2 B, 4,5$ \\
\hline pK039 & pCAG-IoxP-stop-loxP-AmCyan-ires-tTA-WPRE-pA & Fig. $3 E, F$ \\
\hline pK165 & pAAV-RFP-WPRE-pA & Figs. $1 C, D, 7$ \\
\hline pK166 & pAAV-Cre-RFP-WPRE-pA & Fig. 7 \\
\hline pK173 & pAAV-GFPCre-WPRE-pA & Figs. 5,6 \\
\hline pK192 & pCAG-loxP-stop-loxP- $\alpha 2$-chimaerin(WT)TagRFP-pA & Fig. $3 B, C, E, F$ \\
\hline pK193 & pCAG-loxP-stop-loxP- $\alpha 2$-chimaerin(R304G)TagRFP-pA & Fig. $3 B, C, E, F$ \\
\hline pK194 & pCAG-loxP-stop-loxP- $\alpha 1$-chimaerin(WT)TagRFP-pA & Fig. $3 B, C, E$ \\
\hline pK195 & pCAG-loxP-stop-loxP- $\alpha 1$-chimaerin(R304G)TagRFP-pA & Fig. $3 B, C$ \\
\hline pK196 & pCAG-loxP-stop-loxP- $\alpha 2$-chimaerin $(\Delta N)$ TagRFP-pA & Fig. $3 B, C, E$ \\
\hline pK197 & pCAG-loxP-stop-loxP- $\alpha 2$-chimaerin( $\Delta \mathrm{N}+\mathrm{R304G)TagRFP-pA}$ & Fig. $3 B, C$ \\
\hline
\end{tabular}

SDS-polyacrylamide gel electrophoresis and electroblotted to PVDF membranes. The membranes were stained with anti-actin monoclonal antibody (mAb; 1:10,000, mouse; MAB1501, Millipore), anti- $\alpha 2$-chimaerin pAb (1: 20,000, rabbit; Iwasato et al., 2007), and appropriate species-specific HRP-conjugated secondary antibodies; and detected using enhanced chemiluminescence (ECL Plus or ECL Prime, GE Healthcare). Quantification of Western blot analysis was performed using image reader LAS $4000 \mathrm{mini}$ (Fujifilm) and Multi Gauge software (Fujifilm). Expression levels of $\alpha 2$ chimaerin were normalized with those of actin (Figs. 5D, 6D).

\section{Spine retraction assay}

Spine retraction assay was performed as previously reported (Fu et al., 2007) with some modifications. For neuronal labeling, Flpe/FRT-based Supernova vector sets [pK037 $\left(1 \mu \mathrm{g} \mu \mathrm{l}^{-1}\right)$ and pK036 $\left(100 \mathrm{ng} \mu \mathrm{l}^{-1}\right)$ ] were introduced by IUE into the hippocampal pyramidal neurons of progeny of $C h n 1^{\Delta} \alpha 2 / \Delta \alpha 2$ males and $C h n 1^{\Delta} \alpha 2 /+$ females. Organotypic hippocampal slice cultures were prepared from P5 pups, according to a previous report (De Simoni and Yu, 2006). Retraction assay was performed on the sixth day in vitro. For Fc clustering, ephrinA3-Fc (R\&D Systems) and Fc fragment (Jackson Immunoresearch Laboratories) were preclustered with anti-human Fc pAb (Jackson Immunoresearch Laboratories) in a ratio of 1:4.5 and incubated at room temperature for $1 \mathrm{~h}$ before use. The final concentration for ephrinA3-Fc or Fc was $10 \mu \mathrm{g}$ $\mathrm{ml}^{-1}$. Each slice was treated with either preclustered ephrinA3-Fc or Fc for $16 \mathrm{~h}$. After stimulation, slices were fixed with $4 \%$ PFA in $0.1 \mathrm{M} \mathrm{PB}$ for $30 \mathrm{~min}$, and spine density of RFP-expressing CA1 pyramidal neurons was observed by a confocal microscope (Leica).

\section{Contextual fear-conditioning test}

The fear-conditioning test was conducted using a commercially available apparatus (O'Hara \& Company). In the conditioning session (day 1), the mouse was placed in a conditioning chamber $(10 \times 18 \mathrm{~cm})$ in which a steel grid floor was wired to a shock generator. The chamber had opaque walls and was housed in a sound-attenuated box. After $150 \mathrm{~s}$ free exploration, the mouse was exposed to electric footshocks $(0.75 \mathrm{~mA}$, twice, $2 \mathrm{~s}$ each, separated by $90 \mathrm{~s}$ interstimulus interval). Sixty seconds after the second footshock, the mouse was returned to its home cage. The contextual fear-memory test was conducted $24,48,72$, and $96 \mathrm{~h}$ after conditioning (day 2-5). The mouse was placed in the conditioning chamber for 5 min, during which neither tone nor footshock was presented. Images were captured using a video camera and the area (in pixels) over which the mouse moved was measured. Movement that had $<15$ pixel changes in $2 \mathrm{~s}$ was considered "freezing." Total freezing time was measured as an index of fear memory: freezing percentage $=$ (total freezing time/total testing time) $\times 100$. Extinction performance was quantified, normalized to the value at day 2 trial.

\section{Extracellular field potential recording}

Hippocampal slice preparation. Three-month-old male DT- $\alpha 2 \mathrm{KO}$ mice and their control littermates were used. Animals were anesthetized with isoflurane, and the brain was quickly removed after decapitation and placed into ice-cold cutting medium (200 mm sucrose, $4.0 \mathrm{~mm} \mathrm{KCl}, 1.0$ mм NaH${ }_{2} \mathrm{PO}_{4}, 26 \mathrm{~mm} \mathrm{NaHCO}_{3}, 10 \mathrm{~mm} \mathrm{MgSO}_{4}, 0.2 \mathrm{~mm} \mathrm{CaCl}_{2}$, and 10 mu glucose; bubbled with $5 \% \mathrm{CO}_{2}$ and $95 \% \mathrm{O}_{2}$ ). Transverse hippocampal slices (350 $\mu \mathrm{m}$ thickness) were prepared from both hemispheres using a LinearSlicer Pro7 (Dosaka). The slices were incubated in the recording medium (119 $\mathrm{mm} \mathrm{NaCl}, 2.5 \mathrm{~mm} \mathrm{KCl}, 1.0 \mathrm{~mm} \mathrm{NaH}_{2} \mathrm{PO}_{4}, 26.2$ mм $\mathrm{NaHCO}_{3}, 1.3 \mathrm{~mm} \mathrm{MgSO}_{4}, 2.5 \mathrm{~mm} \mathrm{CaCl}_{2}$, and $11 \mathrm{~mm}$ glucose; bubbled with $5 \% \mathrm{CO}_{2}$ and $95 \% \mathrm{O}_{2}$ ) at $30^{\circ} \mathrm{C}$ for $\geq 2 \mathrm{~h}$ before recording.

Extracellular recording. Shaffer collaterals were stimulated at $0.05 \mathrm{~Hz}$ by delivering biphasic current pulses ( $10-60 \mu \mathrm{A}, 0.2 \mathrm{~ms}$ duration). Multiplanar microelectrodes, arranged in an $8 \times 8$ pattern with $150 \mu \mathrm{m}$ spacing, were used for synaptic stimulation and field potential recording. Evoked field responses from the stratum radiatum in the CA1 area were, through a $0.1-10 \mathrm{kHz}$ bandpass filter, recorded at a $20 \mathrm{kHz}$ sampling rate and stored for off-line analysis. Data were acquired and analyzed with MED64 Mobius software (Alpha Med Scientific). Slope of fEPSP and amplitude of presynaptic fiber volley were used for the comparison between genotypes.

\section{Statistical analysis}

Statistical analyses were performed using PASW Statistics version 18 or IBM SPSS Statistics version 19 (IBM). To determine the statistical method, the normal distribution of data was analyzed using the onesample Kolmogorov-Smirnov test. Significance of differences was assessed as follows. For parametrical statistics, two-tailed unpaired Student's $t$ test for two independent samples or ANOVA for multiple independent samples was used. The Tukey-Kramer post hoc test was used after ANOVA indicated a significant difference. For nonparametrical statics, Mann-Whitney $U$ test for two independent samples or KruskalWallis $\mathrm{H}$ test for multiple independent samples was used. $p<0.05$ was considered significant. Values are given as mean \pm SEM $\left({ }^{*} p<0.05\right.$, $\left.{ }^{* *} p<0.01,{ }^{* * *} p<0.001\right)$.

\section{Results \\ $\alpha 2$-Chimaerin deficiency affects dendritic spine morphogenesis in vivo}

We recently reported that dorsal telencephalon (DT)-specific $\alpha 2$ chimaerin KO (DT- $\left.\alpha 2 \mathrm{KO}: \operatorname{Emx} 1^{\mathrm{Cre} /+} ; \mathrm{Chn} 1^{\alpha 2 f l o x /-}\right)$ mice, in which all hippocampal excitatory neurons lack $\alpha 2$-chimaerin from embryonic stages (Iwasato et al., 2000, 2008; Iwata et al., 2014), show an increase in hippocampus-dependent learning (including contextual fear learning) in adults (Iwata et al., 2014). Because $\alpha 2$-chimaerin expression was particularly strong in the hippocampal CA1 region during development (Fig. 1A; Hall et al., 2001), it was likely that the DT- $\alpha 2 \mathrm{KO}$ mice had abnormalities in the development of neuronal circuits in the hippocampus.

To reveal the possible roles of $\alpha 2$-chimaerin in hippocampal circuit development, we performed morphological analyses of the DT- $\alpha 2 \mathrm{KO}$ mouse hippocampus. First, we analyzed the gross morphology of the DT- $\alpha 2 \mathrm{KO}$ hippocampus and found no obvious abnormalities (data not shown). Second, we analyzed axonal projection patterns because we and others have previously reported that $\alpha 2$-chimaerin has critical roles in the axon guidance of the corticospinal tract, spinal central pattern generator, and ocular motor circuits (Beg et al., 2007; Iwasato et al., 2007; Wegmeyer et al., 2007; Miyake et al., 2008). To determine whether DT- $\alpha 2 \mathrm{KO}$ mice show abnormalities in axon guidance in the hippocampus, we visualized the laminar structures of the hippocampus by netrin-G1 and netrin-G2 immunohistochemistry (Fig. $1 B, C)$. Genes for netrin-G1 and netrin-G2 are expressed in a mutually exclusive manner in the brain, and these proteins are present on the axons of distinct pathways (Nishimura-Akiyoshi et al., 2007; Matsukawa et al., 2014). For example, in the hippocampus, axons of entorhinal cortex layer III neurons that terminate on the stratum lacunosum-moleculare of the hippocampus CA1 express netrin-G1, whereas the axons of CA3 
A

Experimental design

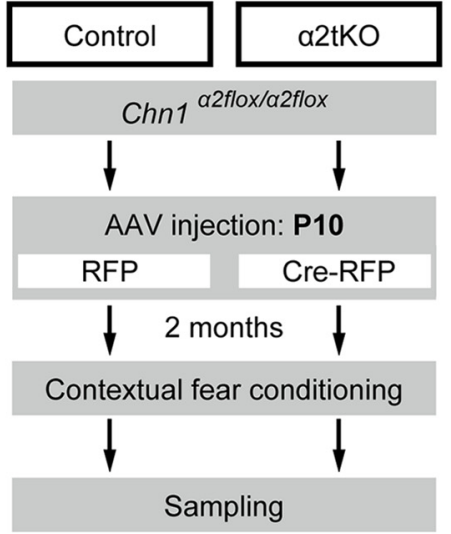

B

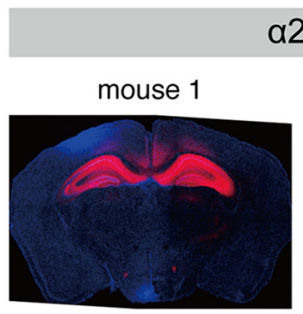

$\alpha 2 \mathrm{tKO}$

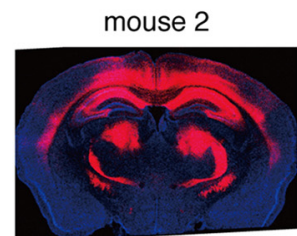

C

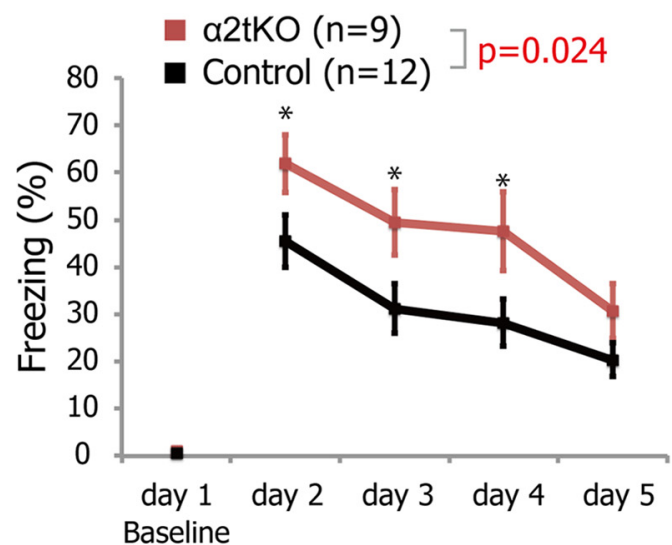

AAV-RFP

or

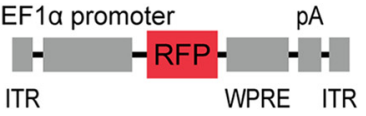

AAV-Cre-RFP

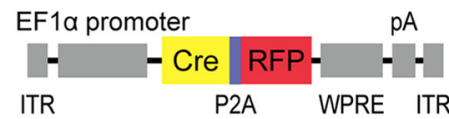

Contextual fear conditioning

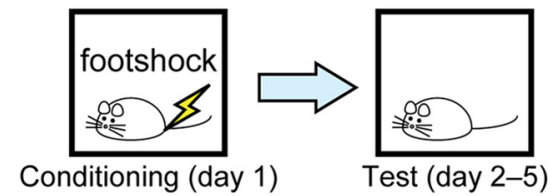

D

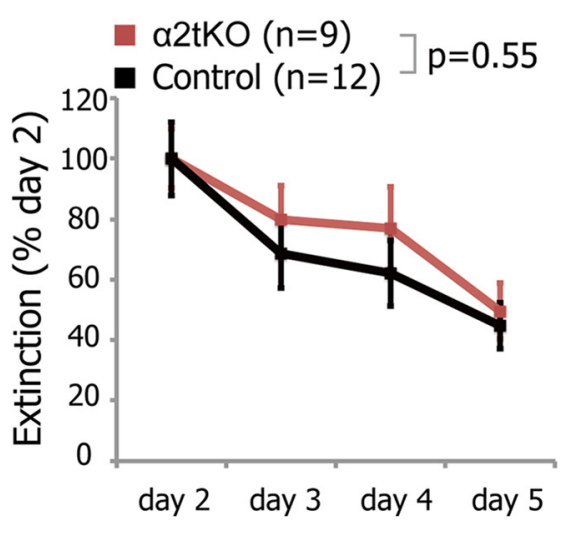

Figure 7. Virus-mediated $\alpha 2$-chimaerin disruption beginning during the juvenile stage enhances contextual fear learning in adulthood. $\boldsymbol{A}$, Schematic depicting the experimental design. To produce $\alpha 2$ tKO and control mice, we bilaterally injected AAV-Cre-RFP and AAV-RFP, respectively, into the dorsal hippocampus of $\alpha 2$-chimaerin-floxed mice at P10. About 2 months after virus injection, we performed the contextual fear-conditioning test and sampling. B. The most restricted (mouse 1 and mouse 3) and the broadest (mouse 2 and mouse 4) RFP expression patterns in $\alpha 2$ tKO and control mice used for the fear-conditioning test. AAV was bilaterally injected to the CA1 region. Note that to achieve maximum hippocampal K0, larger amounts of AAV were used for these experiments than for the experiments in Figures 5 and 6 (see Materials and Methods for detail). However, leakage to outside the hippocampus was rather limited. Scale bar: $\boldsymbol{B}, 1 \mathrm{~mm}$. $\boldsymbol{C}$, Contextual fear learning (day 2-5) was increased in $\alpha 2$ tKO mice compared with control mice (two-way ANOVA; $F_{(1,19)}=5.98,{ }^{*} p<0.05$ for virus; $F_{(3,57)}=17.41,{ }^{* * *} p<0.001$ for day; $F_{(3,57)}=0.54, p=$ 0.66 for virus $\times$ day; asterisk: Bonferroni-Dunn post hoc test ${ }^{*} p<0.05$ for virus). Freezing levels before conditioning (baseline, day 1 ) were not significantly different between groups $(p=0.30$ ). Control: 12 mice; $\alpha 2$ tK0: 9 mice. $D$, Extinction performance was quantified as the percentage freezing normalized to the value of day 2. $\alpha 2$ tK0 mice exhibited normal extinction (two-way ANOVA; $F_{(1,19)}=0.37, p=0.55$ for virus). Data are shown as mean \pm SEM.

neurons that terminate on the stratum radiatum and stratum oriens of CA1 express netrin-G2 (Fig. 1B, left). We found no apparent differences in the expression patterns of the netrin-Gs in the hippocampus between DT- $\alpha 2 \mathrm{KO}$ and their control $\left(C h n 1^{\alpha 2 f l o x /-}\right)$ mice (Fig. $\left.1 B\right)$. Quantitative analyses in CA1 region also showed no differences in intensities of the laminarspecific expressions of netrin-Gs (Fig. 1C), suggesting overtly normal laminar structures in the hippocampus of DT- $\alpha 2 \mathrm{KO}$ mice. We further examined the axonal projection patterns of the hippocampus by the local injection of RFP-expressing AAV into CA3 (Fig. $1 D$ ) or CA1 (Fig. $1 E$ ) of the hippocampus. In both analyses, we found that the axonal projections were similar between DT- $\alpha 2 \mathrm{KO}$ and control mice, although we could not exclude the possibility that there were minor abnormalities in DT- $\alpha 2 \mathrm{KO}$ mice that were not detected by our analyses. Third, we analyzed the dendritic morphologies of hippocampal CA1 pyra- 
midal neurons of DT- $\alpha 2 \mathrm{KO}$ mice in adulthood by using GolgiCox staining (Fig. 1F). There were no significant differences in dendritic complexity and dendritic length between DT- $\alpha 2 \mathrm{KO}$ and control mice, suggesting that morphological aspects of DT$\alpha 2 \mathrm{KO}$ mouse dendrites were overtly normal.

Finally, we focused on the dendritic spines. $\alpha 2$-Chimaerin is a RacGAP. RacGAPs are involved in actin cytoskeleton remodeling, which is associated not only with axonal projections but also with dendritic spine morphogenesis in developing neurons. $\alpha 2$ Chimaerin is enriched in axonal growth cones and in dendritic spines (Iwasato et al., 2007; Shi et al., 2007). We showed that $\alpha 2$-chimaerin expression is particularly strong in the hippocampal CA1 region during the juvenile stage (2-3 weeks old; Fig. 1A), which is an important period for spine morphogenesis (Yuste and Bonhoeffer, 2004). Therefore, it is possible that $\alpha 2$ chimaerin is involved in spinogenesis, particularly in the hippocampal CA1. To test this possibility, we labeled dendritic spines of CA1 pyramidal neurons in DT- $\alpha 2 \mathrm{KO}$ mice (see Materials and Methods), and analyzed their morphology (size and density; Fig. $2 A, B$ ). We found that in DT- $\alpha 2 \mathrm{KO}$ mice in adulthood (2-3 months old), the size (length and volume) and density of spines in apical dendrites were significantly larger than those in the control (Chn1 ${ }^{\alpha 2 f l o x /-}$ ) mice (Fig. 2A). Significant enlargement but not increased density of spines was detected at the juvenile stage (P24) in DT- $\alpha 2 \mathrm{KO}$ mice (Fig. $2 B$ ). In contrast, there were no differences in the spines of basal dendrites between DT- $\alpha 2 \mathrm{KO}$ mice and their littermate controls (data not shown).

We also determined whether the deletion of $\alpha 1$-chimaerin alters spine morphology in vivo because previous in vitro studies reported that overexpression or knockdown of $\alpha 1$-chimaerin affected spine morphology in dissociated hippocampal neurons (Van de Ven et al., 2005; Buttery et al., 2006). DT- $\alpha 1 \mathrm{KO}$ $\left(E m \times 1^{C r e /+} ; C h n 1^{\alpha 1 f l o x /-}\right)$ mice in adulthood exhibited normal spine size and density in hippocampal CA1 pyramidal neurons relative to those in the control $\left(C h n 1^{\alpha 1 f l o x /-}\right)$ mice (Fig. $\left.2 C\right)$, which indicated that $\alpha 1$-chimaerin is dispensable for hippocampal spine morphogenesis in vivo. The discrepancy between our results and previous ones (Van de Ven et al., 2005; Buttery et al., 2006) may be interpreted by differences of experimental conditions (e.g., in vivo vs in vitro). Phenotypic differences between DT- $\alpha 1 \mathrm{KO}$ and DT- $\alpha 2 \mathrm{KO}$ mice could be caused by differences of biochemical properties of $\alpha 1$-chimaerin and $\alpha 2$-chimaerin, which will be described in the following section, and/or by those of temporal expression patterns of two isoforms (Hall et al., 2001; Buttery et al., 2006). Together, these results indicate that $\alpha 2$ chimaerin affects the spine morphology of apical dendrites of hippocampal CA1 pyramidal neurons.

\section{$\alpha 2$-Chimaerin regulates dendritic spine size in RacGAP activity-dependent and $\mathrm{N}$ terminus-dependent manners} To obtain further insight into the molecular mechanisms by which $\alpha 2$-chimaerin participates in spine morphogenesis, we performed single-cell overexpression experiments using the IUEbased Supernova overexpression method (see Materials and Methods), by which we can express a gene of interest in a sparse population of neurons (Fig. 3). Overexpression of wild-type (WT) $\alpha 2$-chimaerin $[\alpha 2(\mathrm{WT}) \mathrm{OE}]$ in the hippocampal pyramidal neurons decreased length and volume but not density of spines in juvenile mice (at P22-P23; Fig. 3B). These results were consistent with the larger size and normal density of DT- $\alpha 2 \mathrm{KO}$ spines during juvenile stage (Fig. 2B). In contrast, overexpression of the RacGAP-inactive mutant of $\alpha 2$-chimaerin [ $\alpha 2(\mathrm{R} 304 \mathrm{G}) \mathrm{OE}$; Hall et al., 2001; Iwasato et al., 2007] failed to alter the spine size or density (Fig. 3B). Both $\alpha 2$-chimaerin (WT) and $\alpha 2$-chimaerin $(\mathrm{R} 304 \mathrm{G})$ were present in dendritic spines (Fig. $3 E, F)$. These results suggest that the RacGAP activity of $\alpha 2$-chimaerin is required for the negative regulation of dendritic spine size in hippocampal neurons during brain development. These data also demonstrate that $\alpha 2$-chimaerin overexpression affects spine morphology through cell-autonomous mechanisms because, in these experiments, overexpression was induced only in a sparse population of neurons primarily in the CA1 region (Fig. 3C).

We also assessed the importance of the $\alpha 2$-specific $\mathrm{N}$ terminus, which contains an $\mathrm{SH} 2$ domain, by overexpression of $\mathrm{N}$ terminus-deleted $\alpha 2$-chimaerin $[\alpha 2$-chimaerin $(\Delta \mathrm{N})]$ or WT $\alpha 1$-chimaerin [ $\alpha 1$-chimaerin (WT)]. We found that positioning of cells expressing either $\alpha 2$-chimaerin $(\Delta \mathrm{N})$ or $\alpha 1$-chimaerin (WT) was abnormal, probably because of excessive cell migration (Fig. 3C). Such ectopic neurons were not observed when we overexpressed RacGAP activity-deficient types [ $\alpha 2$-chimaerin $(\Delta \mathrm{N}$ and R304G) and $\alpha 1$-chimaerin (R304G); Fig. 3C] or in $\alpha 2$ chimaerin $\mathrm{KO}(\alpha 2 \mathrm{KO})$ mice (Fig. $3 D)$. We also compared the subcellular localization of $\alpha 2$-chimaerin $(\Delta \mathrm{N})$ and $\alpha 1$-chimaerin (WT) molecules with that of $\alpha 2$-chimaerin (WT) molecules. $\alpha 1$ Chimaerin (WT) expression was not detected (Fig. 3E), possibly because it was rapidly removed by degradation signals on the $\alpha 1$-chimaerin-specific $\mathrm{N}$ terminus (Marland et al., 2011). On the other hand, $\alpha 2$-chimaerin $(\Delta \mathrm{N})$ was normally localized in cell bodies and dendrites, even in ectopic neurons (Fig. $3 E$ ). Together, our results suggest an important role for the $\alpha 2$ chimaerin-specific $\mathrm{N}$ terminus, which contains an $\mathrm{SH} 2$ domain, for precise regulation of its RacGAP activity. The $\mathrm{SH} 2$ domain significantly contributes to intracellular signaling as a docking site for phosphorylated tyrosine residues on some molecules, such as activated Eph receptors (Cowan et al., 2005). Previous in vitro and structural studies have suggested that the $\mathrm{SH} 2$ domain of $\alpha 2$-chimaerin-specific $\mathrm{N}$ terminus is an autoinhibitory region that inhibits RacGAP function unless the molecule is activated by specific signaling molecules (Canagarajah et al., 2004; ColónGonzález et al., 2008). These features of the $\alpha 2$-chimaerinspecific $\mathrm{N}$ terminus may contribute to the tight regulation of $\alpha$-chimaerin's RacGAP activity. Our results also highlight that $\alpha 1$-chimaerin and $\alpha 2$-chimaerin are regulated in distinct ways in vivo.

\section{a2-Chimaerin mediates ephrinA-induced spine retraction}

We next examined signaling mechanisms upstream of $\alpha 2$ chimaerin in spine morphogenesis. Among many molecules and signaling pathways involved in spine morphogenesis (Dalva et al., 2007; Penzes et al., 2011), we focused on ephrinA3/EphA4 forward signaling as the primary candidate upstream of $\alpha 2$ chimaerin for the following reasons. First, both in vivo and in vitro evidence suggests that $\alpha 2$-chimaerin binds to EphA4 and mediates EphA4 forward signaling in the midline guidance of the corticospinal tract and the spinal central pattern generator axons (Beg et al., 2007; Iwasato et al., 2007; Shi et al., 2007; Wegmeyer et al., 2007). Second, ephrinA3/EphA4 forward signaling is proposed to regulate spine morphogenesis in the developing hippocampus: EphA4 is enriched in the spines of apical dendrites of hippocampal CA1 neurons (Murai et al., 2003; Klein, 2009). EphA4KO mice exhibit increased spine size and density in the apical dendrites of CA1 pyramidal neurons (Murai et al., 2003). EphrinA3KO mice exhibit increased spine size in the apical dendrites of CA1 pyramidal neurons (Carmona et al., 2009). However, it should also be noted that downstream effectors of ephrinA3/EphA4 forward signaling in spine morphogenesis 
are not well understood, and $\alpha$-chimaerin ( $\alpha 1$-chimaerin and $\alpha 2$-chimaerin) has never been interpreted as a downstream mediator of ephrin/Eph (EphA and EphB) signaling in spine morphogenesis.

To test our hypothesis that $\alpha 2$-chimaerin regulates spine morphogenesis as a key mediator of ephrinA3/EphA4 forward signaling, we performed a spine retraction assay using organotypic slice cultures. We prepared hippocampal slices from P5 mice in which we labeled CA1 pyramidal neurons by using the IUE-based Supernova RFP method. Then, we cultured the slice and treated it with preclustered ephrinA3-Fc (Fig. 4; see Materials and Methods). Consistent with previous reports (Fu et al., 2007), ephrinA3 stimulation induced a reduction in the numbers of spines in control $\left(\mathrm{Chnl}^{\Delta} \alpha 2 /+\right)$ mouse neurons (Fig. 4C). In contrast, ephrinA3-induced spine retraction was suppressed in $\alpha 2 \mathrm{KO}$ mouse neurons (Fig. 4C). These results suggest that $\alpha 2$ chimaerin mediates ephrinA-induced spine retraction and supports our hypothesis that $\alpha 2$-chimaerin acts as a downstream effector of ephrinA3/EphA4 forward signaling in spine morphogenesis in the developing hippocampus.

\section{$\alpha 2$-Chimaerin function in the juvenile stage affects morphological features of spines}

To determine whether $\alpha 2$-chimaerin function in late postnatal stages (juvenile and adolescence), which is the important period for spinogenesis, affects morphological features of spines, we constructed an AAV vector (AAV-GFPCre) that expresses GFPfused nuclear localization signal-tagged Cre recombinase under the control of EF1 $\alpha$ promoter (Fig. 5). We unilaterally injected the AAV-GFPCre into the dorsal hippocampus of $\alpha 2$-chimaerinfloxed mice $\left(\mathrm{Chn} 1^{\alpha 2 f l o x /-}\right)$ and $\mathrm{Chn} 1^{+/-}$mice at P10 (Fig. 5A). Fourteen days after virus injection (at P24), strong GFP expression indicating Cre expression was observed in the hippocampal CA1 pyramidal layers (Fig. 5B). We used the IUE-based Supernova RFP method (Fig. $5 C$ ) to label CA1 neurons, which then appeared bright and sparse. We then compared the dendritic spine morphologies of GFP-expressing $\left(\mathrm{Cre}^{+}\right) \mathrm{CA} 1$ pyramidal neurons in $\alpha 2$-chimaerin-floxed mice ( $\alpha 2$-chimaerin temporalspecific KO: $\alpha 2 \mathrm{tKO}$ neurons) with those in $\mathrm{ChnI}^{+/-}$mice (control neurons). We found that the spine size (length and volume) was enlarged in $\alpha 2 \mathrm{tKO}$ neurons in the juvenile stage (at P24; Fig. $5 E)$. These results were similar to those from the DT- $\alpha 2 \mathrm{KO}$ mice at P24 (Fig. 2B), which indicated the importance of $\alpha 2$-chimaerin function during the juvenile stage (between P10 and P24) in determination of the spine size.

\section{Lack of $\alpha 2$-chimaerin function in adulthood fails to affect morphological features of spines}

Spines are highly dynamic even in adulthood and change their size and density in response to a variety of stimuli. Therefore, it is unclear whether spine phenotypes of DT- $\alpha 2 \mathrm{KO}$ mice in adulthood (Fig. 2A) are caused by a lack of $\alpha 2$-chimaerin during development and/or in adulthood. To examine the roles of $\alpha 2$ chimaerin in adulthood, we deleted $\alpha 2$-chimaerin only in adulthood. We unilaterally injected the AAV-GFPCre vector into the dorsal hippocampus of $\alpha 2$-chimaerin-floxed $\left(\mathrm{Chn} 1^{\alpha 2 f l o x /-}\right)$ and $\mathrm{Chn1}{ }^{+/-}$mice in adulthood (2 months old; Fig. 6). Fourteen days after virus injection, strong GFP expression indicating Cre expression was observed in the hippocampal CA1 pyramidal layers (Fig. 6B). We sparsely labeled CA1 pyramidal neurons with DiI and compared spine morphologies of GFP-expressing $\left(\mathrm{Cre}^{+}\right)$ CA1 pyramidal neurons in $\alpha 2$-chimaerin-floxed mice $(\alpha 2 \mathrm{tKO}$ neurons) with those in $\mathrm{Chn1}^{+/-}$mice (control neurons; Fig. 6C).
We found that there were no differences in spine length, volume, and density between $\alpha 2 \mathrm{tKO}$ and control neurons (Fig. 6E). Thus, $\alpha 2$-chimaerin function in adulthood was dispensable for the morphological features of adult spines. These results were consistent with the low levels of $\alpha 2$-chimaerin expression in the adult hippocampus (Fig. 1A). Together, these findings suggested that $\alpha 2$-chimaerin function in late postnatal development is important for the determination of the basal morphological features in adulthood.

\section{$\alpha 2$-Chimaerin disruption beginning during the juvenile stage increases contextual fear learning}

We recently reported that $\alpha 2$-chimaerin is involved in cognitive development. When $\alpha 2$-chimaerin is deleted from the embryonic stage, contextual fear learning, a hippocampus-dependent learning (Kim and Fanselow, 1992; Phillips and LeDoux, 1992), increases in adult mice (2-3 months old), whereas $\alpha 2$-chimaerin disruption in adulthood does not affect contextual memory (Iwata et al., 2014). In the present study, we found that the deletion of $\alpha 2$-chimaerin beginning either during the embryonic or juvenile stage leads to an increase of spine size (and density), whereas $\alpha 2$-chimaerin disruption in adulthood did not affect spine morphology in the hippocampus (Figs. 2, 5, 6).

To determine whether the deletion of $\alpha 2$-chimaerin beginning during the juvenile stage would also lead to the enhancement of hippocampus-dependent learning, we generated temporally controlled $\alpha 2$-chimaerin-deficient $(\alpha 2 \mathrm{tKO})$ mice (Fig. 7). We made AAV-Cre-RFP and AAV-RFP vectors, which express both Cre and RFP, and RFP alone, respectively, under the control of the EF1 $\alpha$ promoter. To produce $\alpha 2 \mathrm{tKO}$ and control mice, we bilaterally injected AAV-Cre-RFP and AAV-RFP, respectively, into the dorsal hippocampus of $\alpha 2$-chimaerin-floxed mice $\left(C h n 1^{\alpha 2 f l o x / \alpha 2 f l o x}\right)$ at P10. About 2 months after virus injection, we performed a contextual fear-conditioning test. The timeline of the AAV injection and fear-conditioning test and sampling are shown in Figure 7A. The $\alpha 2 \mathrm{tKO}$ mice exhibited an increase in contextual fear memory relative to that in control mice (Fig. $7 C$ ). In contrast, extinction learning was not different between the two groups (Fig. 7D). These phenotypes were similar to those observed in $\alpha 2 \mathrm{KO}$ and DT- $\alpha 2 \mathrm{KO}$ mice (Iwata et al., 2014). Together, our present and previous findings suggest that $\alpha 2$ chimaerin function in the hippocampus during the late postnatal period contributes to establishing normal cognitive ability in adulthood.

Many studies, such as those using animals housed in enriched environments, have suggested potential correlations among spine density, efficacy of synaptic transmission, and learning ability of the hippocampus (Rampon et al., 2000; van Praag et al., 2000). Therefore, we hypothesized that DT- $\alpha 2 \mathrm{KO}$ mice, which exhibited increases in the size and density of hippocampal spines (Fig. 2A) and greater hippocampus-dependent learning (Iwata et al., 2014), may also exhibit increased excitatory synaptic transmission in the hippocampus. To test this possibility, we evaluated the synapse strength of the DT- $\alpha 2 \mathrm{KO}$ mouse hippocampus in adulthood. As expected, excitatory synaptic transmission at the CA3-CA1 pathway was significantly increased in DT- $\alpha 2 \mathrm{KO}$ mice (Fig. 8A). On the other hand, the paired-pulse ratio, which is a widely used indicator of presynaptic function involved in evoked release mechanism, was not different between genotypes (Fig. $8 B$ ). Increased size and density of spines (Fig. $2 A$ ) may result in increased basal synaptic transmission in the CA3-CA1 synapses (Fig. $8 A$ ) in DT- $\alpha 2 \mathrm{KO}$ mice, which in turn may be ascribed to a higher learning ability in these mice (Iwata et al., 2014). 
A

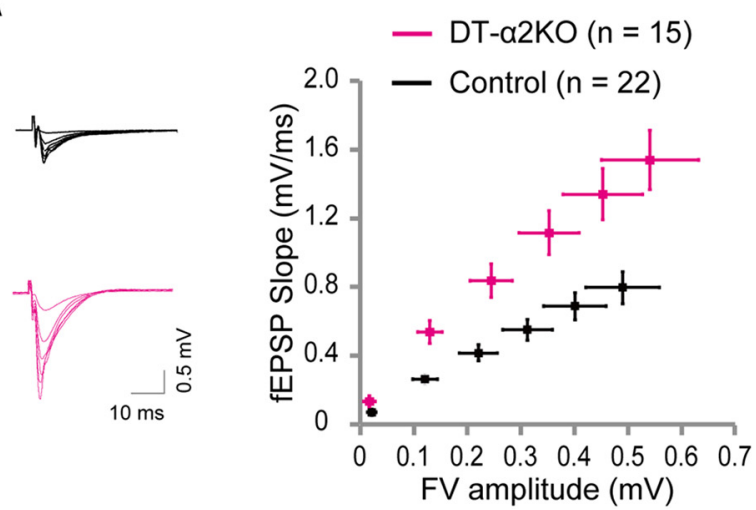

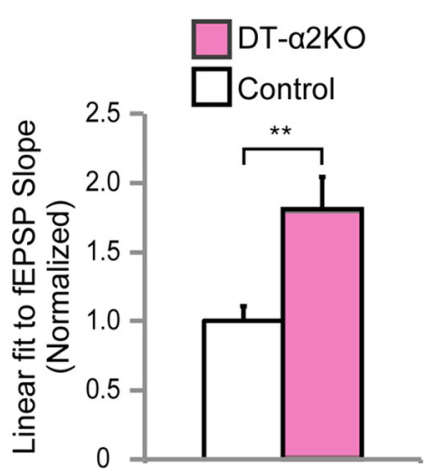

B

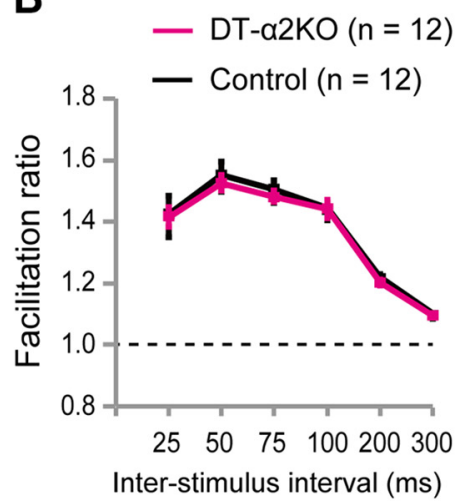

Figure 8. Enhanced synaptic transmission in the hippocampus of DT- $\alpha 2 \mathrm{~K} 0$ mice. A, Basal synaptic transmission was increased in the CA3-CA1 pathway in hippocampal slice derived from DT- $\alpha 2 \mathrm{~K} 0$ mice. Representative traces of field potentials recorded in the stratum radiatum of the CA1 region in response to different stimulus intensities $(10-60 \mu \mathrm{A})$. Input- output relations were significantly different between control and DT- $\alpha 2$ KO slices. FV, Fiber volley. Linear fits to graded increase of fEPSP slopes were compared between genotypes (two-tailed unpaired Student's $t$ test; ${ }^{* *} p<0.01$ ). Control: 22 slices, 16 mice; DT- $\alpha 2$ KO: 15 slices, 10 mice. B, Presynaptic facilitation induced by paired stimuli, with the intervals of $25-300$ ms, was not significantly different between DT- $\alpha 2$ K0 and their control mice (tw0-way ANOVA; $F_{(1,22)}=0.038, p=0.84$ for genotype). Control: 12 slices, 8 mice; DT- $\alpha 2$ KO: 12 slices, 6 mice. Data are shown as mean \pm SEM.

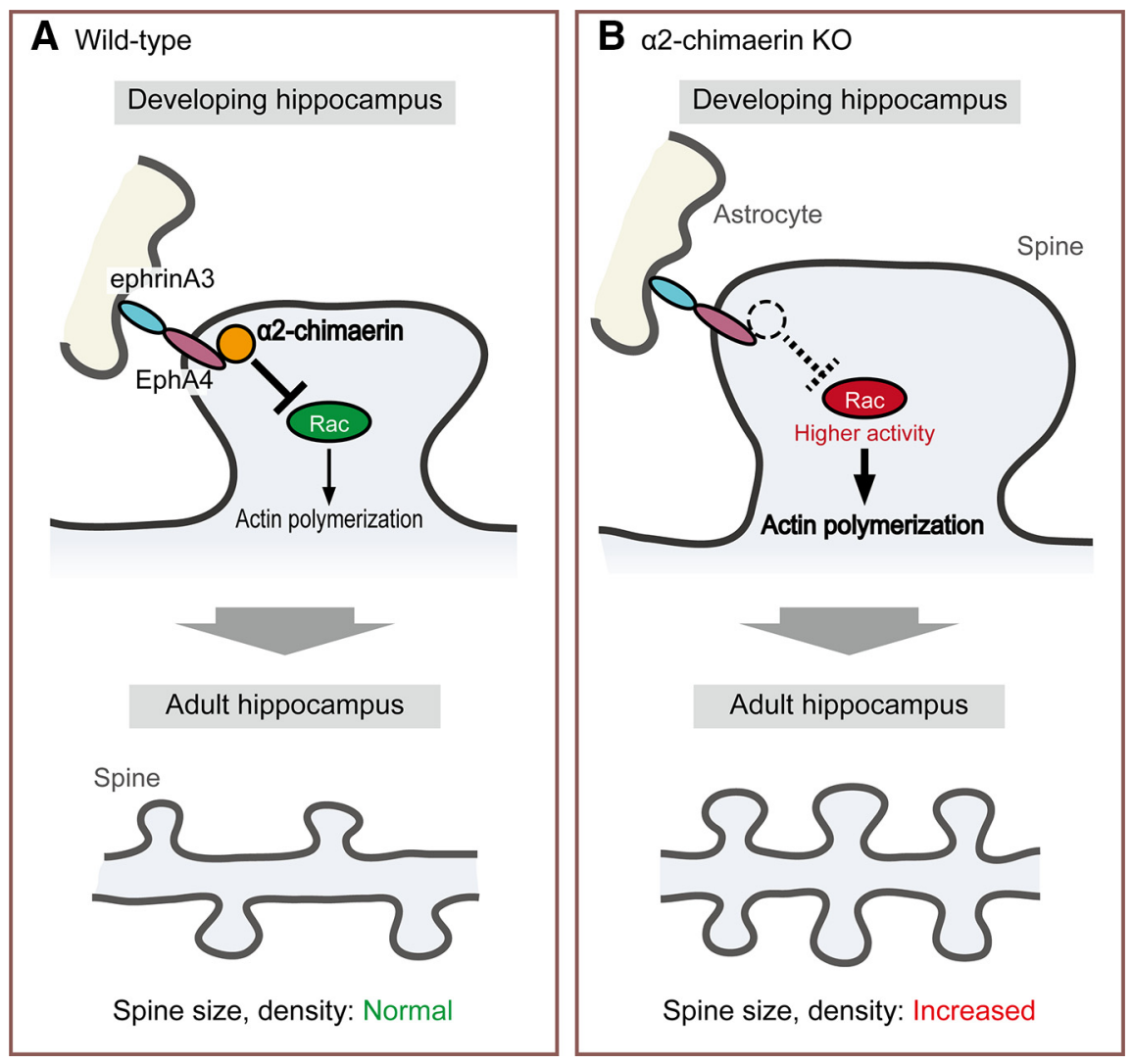

Figure 9. Model of RacGAP $\alpha 2$-chimaerin signaling in the developing hippocampus that contributes to determination of the morphological features of adult spines. $\boldsymbol{A}$, In the developing hippocampus of WT mice, $\alpha 2$-chimaerin regulates spine morphogenesis by inactivating Rac, a positive regulator of actin polymerization, most likely as a critical mediator of ephrinA3/EphA4 signaling. It is suggested that ephrinA3 on astrocytes activates EphA4 on the postsynaptic neurons and restricts the growth of dendritic spines in the developing hippocampus (Murai et al., 2003). B, In the developing hippocampus of $\alpha 2$-chimaerin K0 mice, the EphA forward signaling fails to suppress Rac activity due to the lack of $\alpha 2$-chimaerin, which then accelerates actin polymerization, leading to increased spine size and density in adulthood.

\section{Discussion}

RacGAP $\alpha 2$-chimaerin regulates spine morphogenesis as a mediator of EphA forward signaling in the developing hippocampus

We and others recently identified RacGAP $\alpha 2$-chimaerin as an important regulator of axon guidance of motor circuits (Beg et al., 2007; Iwasato et al., 2007; Shi et al., 2007; Wegmeyer et al., 2007), cortical neuron migration (Ip et al., 2012), and learning and memory (Iwata et al., 2014). Here we showed that $\alpha 2$-chimaerin is involved in spine morphogenesis. Hippocampal excitatory neurons in which $\alpha 2$-chimaerin is disrupted during development exhibited increased size (and density) of dendritic spines (Figs. $2 A, B$, 5 ). Overexpression of $\alpha 2$-chimaerin in the hippocampal pyramidal neurons during development decreased spine size. In contrast, overexpression of the RacGAP-inactive mutant of $\alpha 2$ chimaerin [ $\alpha 2$-chimaerin(R304G)] failed to alter spine size (Fig. 3), suggesting that $\alpha 2$-chimaerin regulates spine morphogenesis in a RacGAP activitydependent manner in the developing hippocampus.

In the dendrites of hippocampal CA1 neurons, ephrinA3/EphA4 forward signaling has been reported to play an important role in neuroglial cross-talk for spine morphogenesis (see Results for detailed background information). In hippocampal slice cultures, ephrinAinduced spine retraction is suppressed by $\alpha 2$-chimaerin deletion (Fig. 4 ), suggesting that $\alpha 2$-chimaerin mediates ephrin/EphA-dependent spine morphogenesis (Fig. 9). Some synaptic molecules, such as ephexin1, Cdk5, and PLC $\gamma$, are also known to be involved in EphA4-mediated dendritic spine retraction (Fu et al., 2007; Zhou et al., 2007). Cdk5 can interact with $\alpha 2$-chimaerin (Brown et al., 2004), whereas PLC $\gamma$ generates DAG, which can bind the $\alpha$-chimaerin C1 domain (Buttery et al., 2006). These molecules may cooperate with $\alpha 2$-chimaerin in EphA4-dependent spine formation during development. 
$\alpha 2$-Chimaerin function during late postnatal development is a determinant of adult spine morphological features

Importantly, our findings also suggest that $\alpha 2$-chimaerin is involved in developmental mechanisms that determine the morphological features of spines in adulthood. $\alpha 2$-Chimaerin disruption beginning during the embryonic stage results in an increase in spine sizes and density in the adult hippocampus (Fig. $2 A$ ), whereas spine morphologies are unaltered when $\alpha 2$ chimaerin is deleted only in adulthood (Fig. 6). In mice harboring an $\alpha 2$-chimaerin deletion from the embryonic stage or early juvenile stage (P10), spine size increased at the juvenile stage (P24; Figs. 2B, 5), suggesting an important role of $\alpha 2$-chimaerin in early spinogenesis. Conversely, spine density is normal in these juvenile-stage mice (Figs. $2 B, 5$ ), suggesting that $\alpha 2$-chimaerin affects spine density during adolescence (between juvenile stage and adulthood). In the mouse forebrain, the number of dendritic spines increases until $\sim 4$ weeks of age (juvenile stage) and then decreases until adulthood (Nimchinsky et al., 2001; Zuo et al., 2005). This extensive spine loss appears to be impaired in the absence of $\alpha 2$-chimaerin function. It is probable that $\alpha 2$ chimaerin is required for spine pruning/retraction during the adolescent stage. In support of this, we found in vitro that ephrin/ EphA forward signaling-dependent spine pruning/retraction in the developing hippocampus was suppressed in the absence of $\alpha 2$-chimaerin (Fig. 4). Alternatively, adolescent $\alpha 2$-chimaerin could be involved in suppressing the formation of new spines, although these two possibilities are not mutually exclusive. Analyses of spine dynamics in the hippocampus during the adolescent stage could reveal the precise roles of $\alpha 2$-chimaerin in spinogenesis. Altogether, $\alpha 2$-chimaerin signaling during late postnatal development (juvenile and adolescent stages) contributes to the determination of the basal morphological features (e.g., size, density) of hippocampal spines in adulthood (Fig. 9).

\section{Rac activity-mediated spine morphogenesis and cognitive development}

Recent studies, mostly of neurodevelopmental disorders, such as autism spectrum disorders and schizophrenia in humans and their animal models, have led to an attractive hypothesis that spinogenesis during development forms the basis of adult cognition. In particular, roles of Rac and its regulators (e.g., RacGAPs and RacGEFs) are a topic of focus in spine morphogenesis and cognitive ability (Penzes et al., 2011; Ba et al., 2013). Animal models, most of which are global KO mice, have largely contributed to insights into the mechanisms underlying neurodevelopmental disorders. For example, KO mice of several RacGAPs (BCR, ABR, and srGAP2) and RacGEFs (kalirin-7 and $\alpha$-PIX) were used (Ma et al., 2008; Cahill et al., 2009; Oh et al., 2010; Carlson et al., 2011; Ramakers et al., 2012). However, because Rac signaling plays a wide variety of roles in the development and function of neuronal circuit (Luo, 2000; Bai et al., 2015), the global KO strategy is critically limited in its ability to associate a specific development role (e.g., spinogenesis) of a Rac-related molecule with a specific behavior in the mouse. For example, learning deficits in a global $\mathrm{KO}$ mouse may be ascribed to impairment in adult function (e.g., synaptic plasticity) of the molecule, and/or impairment of embryonic function (e.g., axon guidance) in other brain areas.

We have addressed the issue by generating and analyzing a series of temporally and spatially restricted deletions of $\alpha 2$ chimaerin in mice. In our recent study, we revealed that DT$\alpha 2 \mathrm{KO}$ mice, in which all hippocampal excitatory neurons lack $\alpha 2$-chimaerin from embryonic stages, exhibit an increase in hippocampus-dependent learning, such as contextual fear learning, whereas learning is not altered when $\alpha 2$-chimaerin is deleted only in adulthood (Iwata et al., 2014). In the present study, we found that, in the DT- $\alpha 2 \mathrm{KO}$ mouse hippocampus in adulthood, spine size and density of CA1 neurons are increased (Fig. 2A), whereas apparent abnormalities are not observed in the axonal projection or dendritic morphologies (Fig. 1). Moreover, spine morphologies are unaltered by adult-specific deletion of $\alpha 2$ chimaerin (Fig. 6).

In the present study, we further clarified the developmental role of $\alpha 2$-chimaerin in cognition by demonstrating that AAVmediated deletion of $\alpha 2$-chimaerin in the hippocampus and surrounding areas starting from $\mathrm{P} 10$ results in increased contextual fear learning in adulthood (Fig. 7). We also showed that AAVmediated deletion of $\alpha 2$-chimaerin in the hippocampus starting from P10 resulted in enlarged spines at the juvenile stage (Fig. 5). Although spine size and density in these mice [ $\alpha 2 \mathrm{tKO}$ (AAV at P10) mice] were not directly examined in adulthood, it is reasonable to assume that they increased in a similar manner as those in DT- $\alpha 2 \mathrm{KO}$ mice. AAV-mediated $\alpha 2$-chimaerin deletion after P10 resulted in spine morphological phenotypes (size and density) at P24 that were similar to those of DT- $\alpha 2 \mathrm{KO}$ mice at the same age (Figs. 2B, 5E). These results suggested that AAV injection at P10 achieved sufficient deletion of $\alpha 2$-chimaerin before P24; therefore, spine morphological changes that occurred after P24 should also be similar between $\alpha 2 \mathrm{tKO}$ (AAV at P10) mice and DT- $\alpha 2 \mathrm{KO}$ mice.

Together, we clearly showed that, in the mouse, hippocampal $\alpha 2$-chimaerin acts in the late postnatal stages (juvenile and adolescence) to establish both the baseline level of the dendritic spine morphology and normal contextual fear-learning ability in adulthood. Our data in mouse models provide evidence to support the hypothesis that Rac activity-mediated spine morphogenesis during development is a critical determinant of cognitive ability in adulthood.

\section{Distinct roles of $\alpha 1$-chimaerin and $\alpha 2$-chimaerin in spinogenesis}

The $\alpha$-chimaerin isoforms $\alpha 1$-chimaerin and $\alpha 2$-chimaerin exhibit distinct biochemical properties in vitro (Lim et al., 1992; Hall et al., 2001; Buttery et al., 2006). However, the isoformspecific roles of $\alpha$-chimaerin in vivo are not well understood. By generating and analyzing isoform-specific $\mathrm{KO}$ mice, we recently reported that the $\alpha 2$ isoform but not the $\alpha 1$ isoform is involved in the regulation of gait pattern, locomotor activity, and contextual fear learning of mice (Iwata et al., 2014). Here we showed that the $\alpha 2$ isoform but not the $\alpha 1$ isoform is involved in the spinogenesis of hippocampal CA1 neurons in vivo. DT- $\alpha 2 \mathrm{KO}$ mice, but not DT- $\alpha 1 \mathrm{KO}$ mice, exhibited increased size and density of spines of hippocampal CA1 neurons (Fig. 2). On the other hand, IUEmediated overexpression of the $\alpha 1$ isoform but not that of the $\alpha 2$ isoform in hippocampal CA1 neurons resulted in abnormal localization of these neurons (Fig. 3C), most likely through excessive cell migration. $\alpha 1$-Chimaerin and $\alpha 2$-chimaerin share the $\mathrm{C}$ terminus, which contains the $\mathrm{C} 1$ and RacGAP domains; however, their N termini are distinct (Yang and Kazanietz, 2007). The ectopic localization of neurons overexpressing the $\alpha 1$ isoform requires the functional RacGAP domain of this $\alpha 1$ isoform because abnormally localized neurons were not observed when RacGAP-inactive $\alpha 1$-chimaerin [ $\alpha 1$-chimaerin (R304G)] was overexpressed (Fig. 3C). Furthermore, it is likely that the absence of the $\alpha 2$-specific $\mathrm{N}$ terminus, which contains an $\mathrm{SH} 2$ domain, and not the presence of the $\alpha 1$-specific $\mathrm{N}$ terminus, is critical for 
the role of $\alpha 1$-chimaerin in cell positioning, because ectopic neurons were also observed when $\alpha 2$-chimaerin $(\Delta \mathrm{N})$ was overexpressed (Fig. 3C). The $\mathrm{SH} 2$ domain provides a docking site for phosphorylated tyrosine residues on some molecules, such as activated Eph receptors, and plays an important role in intracellular signaling (Cowan et al., 2005). Previous in vitro and structural studies suggest that the $\alpha 2$-chimaerin-specific $\mathrm{N}$ terminus, including the SH2 domain, has an autoinhibitory function that blocks RacGAP activity when the molecule needs to be inactive (Canagarajah et al., 2004; Colón-González et al., 2008). Overexpression of $\alpha 2$-chimaerin did not cause abnormal cell positioning (Fig. 3C,E), possibly because the RacGAP activity of $\alpha 2$-chimaerin was inhibited unless ephrinA3/EphA4 signaling at the synapse unlocked the autoinhibitory function of the $\mathrm{N}$ terminus.

In conclusion, the present findings suggest that $\alpha 2$-chimaerindependent spine remodeling during late postnatal development contributes to the adjustment of the baseline and framework of spine morphology (size and density) in adulthood, in addition to cognitive ability. Further studies are required to elucidate precise roles of $\alpha 2$ chimaerin and other Rac-related molecules in spine morphogenesis and cognition. Our global and conditional $\alpha$-chimaerin $\mathrm{KO}$ mice are promising experimental models for clarifying these issues.

\section{References}

Ba W, van der Raadt J, Nadif Kasri N (2013) Rho GTPase signaling at the synapse: implications for intellectual disability. Exp Cell Res 319:23682374. CrossRef Medline

Bai Y, Xiang X, Liang C, Shi L (2015) Regulating Rac in the nervous system: molecular function and disease implication of Rac GEFs and GAPs. Biomed Res Int 2015:632450. CrossRef Medline

Beg AA, Sommer JE, Martin JH, Scheiffele P (2007) alpha2-Chimaerin is an essential EphA4 effector in the assembly of neuronal locomotor circuits. Neuron 55:768-778. CrossRef Medline

Bourne JN, Harris KM (2008) Balancing structure and function at hippocampal dendritic spines. Annu Rev Neurosci 31:47-67. CrossRef Medline

Brown M, Jacobs T, Eickholt B, Ferrari G, Teo M, Monfries C, Qi RZ, Leung T, Lim L, Hall C (2004) $\alpha 2$-Chimaerin, cyclin-dependent kinase 5/p35, and its target collapsin response mediator protein- 2 are essential components in semaphorin 3A-induced growth-cone collapse. J Neurosci 24: 8994-9004. CrossRef Medline

Buttery P, Beg AA, Chih B, Broder A, Mason CA, Scheiffele P (2006) The diacylglycerol-binding protein alphal-chimaerin regulates dendritic morphology. Proc Natl Acad Sci U S A 103:1924-1929. CrossRef Medline

Cahill ME, Xie Z, Day M, Photowala H, Barbolina MV, Miller CA, Weiss C, Radulovic J, Sweatt JD, Disterhoft JF, Surmeier DJ, Penzes P (2009) Kalirin regulates cortical spine morphogenesis and disease-related behavioral phenotypes. Proc Natl Acad Sci U S A 106:13058-13063. CrossRef Medline

Canagarajah B, Leskow FC, Ho JY, Mischak H, Saidi LF, Kazanietz MG, Hurley JH (2004) Structural mechanism for lipid activation of the Racspecific GAP, beta2-chimaerin. Cell 119:407-418. CrossRef Medline

Carlson BR, Lloyd KE, Kruszewski A, Kim IH, Rodriguiz RM, Heindel C, Faytell M, Dudek SM, Wetsel WC, Soderling SH (2011) WRP/srGAP3 facilitates the initiation of spine development by an inverse F-BAR domain, and its loss impairs long-term memory. J Neurosci 31:2447-2460. CrossRef Medline

Carmona MA, Murai KK, Wang L, Roberts AJ, Pasquale EB (2009) Glial ephrin-A3 regulates hippocampal dendritic spine morphology and glutamate transport. Proc Natl Acad Sci U S A 106:12524-12529. CrossRef Medline

Charrier C, Joshi K, Coutinho-Budd J, Kim JE, Lambert N, de Marchena J, Jin WL, Vanderhaeghen P, Ghosh A, Sassa T, Polleux F (2012) Inhibition of SRGAP2 function by its human-specific paralogs induces neoteny during spine maturation. Cell 149:923-935. CrossRef Medline

Cheadle L, Biederer T (2012) The novel synaptogenic protein Farp1 links postsynaptic cytoskeletal dynamics and transsynaptic organization. J Cell Biol 199:985-1001. CrossRef Medline
Colón-González F, Leskow FC, Kazanietz MG (2008) Identification of an autoinhibitory mechanism that restricts $\mathrm{C} 1$ domain-mediated activation of the Rac-GAP alpha2-chimaerin. J Biol Chem 283:35247-35257. CrossRef

Cowan CW, Shao YR, Sahin M, Shamah SM, Lin MZ, Greer PL, Gao S, Griffith EC, Brugge JS, Greenberg ME (2005) Vav family GEFs link activated Ephs to endocytosis and axon guidance. Neuron 46:205-217. CrossRef Medline

Dalva MB, McClelland AC, Kayser MS (2007) Cell adhesion molecules: signalling functions at the synapse. Nat Rev Neurosci 8:206-220. CrossRef Medline

Datwani A, Iwasato T, Itohara S, Erzurumlu RS (2002) NMDA receptordependent pattern transfer from afferents to postsynaptic cells and dendritic differentiation in the barrel cortex. Mol Cell Neurosci 21:477-492. CrossRef Medline

De Simoni A, Yu LM (2006) Preparation of organotypic hippocampal slice cultures: interface method. Nat Protoc 1:1439-1445. CrossRef Medline

Dong JM, Smith P, Hall C, Lim L (1995) Promoter region of the transcriptional unit for human alpha 1-chimaerin, a neuron-specific GTPase-activating protein for p21rac. Eur J Biochem 227:636-646. CrossRef Medline

Ethell IM, Pasquale EB (2005) Molecular mechanisms of dendritic spine development and remodeling. Prog Neurobiol 75:161-205. CrossRef Medline

Fu WY, Chen Y, Sahin M, Zhao XS, Shi L, Bikoff JB, Lai KO, Yung WH, Fu AK, Greenberg ME, Ip NY (2007) Cdk5 regulates EphA4-mediated dendritic spine retraction through an ephexin1-dependent mechanism. Nat Neurosci 10:67-76. CrossRef Medline

Glantz LA, Lewis DA (2000) Decreased dendritic spine density on prefrontal cortical pyramidal neurons in schizophrenia. Arch Gen Psychiatry 57:65-73. CrossRef Medline

Hall C, Monfries C, Smith P, Lim HH, Kozma R, Ahmed S, Vanniasingham V, Leung T, Lim L (1990) Novel human brain cDNA encoding a 34,000 Mr protein $\mathrm{n}$-chimaerin, related to both the regulatory domain of protein kinase $\mathrm{C}$ and $\mathrm{BCR}$, the product of the breakpoint cluster region gene. J Mol Biol 211:11-16. CrossRef Medline

Hall C, Sin WC, Teo M, Michael GJ, Smith P, Dong JM, Lim HH, Manser E, Spurr NK, Jones TA (1993) Alpha 2-chimerin, an SH2-containing GTPase-activating protein for the ras-related protein $\mathrm{p} 21 \mathrm{rac}$ derived by alternate splicing of the human $\mathrm{n}$-chimerin gene, is selectively expressed in brain regions and testes. Mol Cell Biol 13:4986-4998. Medline

Hall C, Michael GJ, Cann N, Ferrari G, Teo M, Jacobs T, Monfries C, Lim L (2001) $\alpha 2$-Chimaerin, a Cdc42/Rac1 regulator, is selectively expressed in the rat embryonic nervous system and is involved in neuritogenesis in N1E-115 neuroblastoma cells. J Neurosci 21:5191-5202. Medline

Ip JP, Shi L, Chen Y, Itoh Y, Fu WY, Betz A, Yung WH, Gotoh Y, Fu AK, Ip NY (2012) $\alpha 2$-Chimaerin controls neuronal migration and functioning of the cerebral cortex through CRMP-2. Nat Neurosci 15:39-47. CrossRef Medline

Ishizuka N, Weber J, Amaral DG (1990) Organization of intrahippocampal projections originating from CA3 pyramidal cells in the rat. J Comp Neurol 295:580-623. CrossRef Medline

Iwasato T, Datwani A, Wolf AM, Nishiyama H, Taguchi Y, Tonegawa S, Knöpfel T, Erzurumlu RS, Itohara S (2000) Cortex-restricted disruption of NMDAR1 impairs neuronal patterns in the barrel cortex. Nature 406: 726-731. CrossRef Medline

Iwasato T, Katoh H, Nishimaru H, Ishikawa Y, Inoue H, Saito YM, Ando R, Iwama M, Takahashi R, Negishi M, Itohara S (2007) Rac-GAP alphachimerin regulates motor-circuit formation as a key mediator of EphrinB3/EphA4 forward signaling. Cell 130:742-753. CrossRef Medline

Iwasato T, Inan M, Kanki H, Erzurumlu RS, Itohara S, Crair MC (2008) Cortical adenylyl cyclase 1 is required for thalamocortical synapse maturation and aspects of layer IV barrel development. J Neurosci 28:59315943. CrossRef Medline

Iwata R, Ohi K, Kobayashi Y, Masuda A, Iwama M, Yasuda Y, Yamamori H, Tanaka M, Hashimoto R, Itohara S, Iwasoto T (2014) RacGAP alpha2chimaerin function in development adjusts cognitive ability in adulthood. Cell Rep 8:1257-1264. CrossRef Medline

Kasai H, Fukuda M, Watanabe S, Hayashi-Takagi A, Noguchi J (2010) Structural dynamics of dendritic spines in memory and cognition. Trends Neurosci 33:121-129. CrossRef Medline

Kim JJ, Fanselow MS (1992) Modality-specific retrograde amnesia of fear. Science 256:675-677. CrossRef Medline 
Klein R (2009) Bidirectional modulation of synaptic functions by Eph/ephrin signaling. Nat Neurosci 12:15-20. CrossRef Medline

Lim HH, Michael GJ, Smith P, Lim L, Hall C (1992) Developmental regulation and neuronal expression of the mRNA of rat n-chimaerin, a p21rac GAP:cDNA sequence. Biochem J 287:415-422. CrossRef Medline

Luo L (2000) Rho GTPases in neuronal morphogenesis. Nat Rev Neurosci 1:173-180. CrossRef Medline

Ma XM, Kiraly DD, Gaier ED, Wang Y, Kim EJ, Levine ES, Eipper BA, Mains RE (2008) Kalirin-7 is required for synaptic structure and function. J Neurosci 28:12368-12382. CrossRef Medline

Marland JR, Pan D, Buttery PC (2011) Rac GTPase-activating protein (Rac GAP) alpha1-chimaerin undergoes proteasomal degradation and is stabilized by diacylglycerol signaling in neurons. J Biol Chem 286:199-207. CrossRef Medline

Mataga N, Mizuguchi Y, Hensch TK (2004) Experience-dependent pruning of dendritic spines in visual cortex by tissue plasminogen activator. Neuron 44:1031-1041. CrossRef Medline

Matsukawa H, Akiyoshi-Nishimura S, Zhang Q, Luján R, Yamaguchi K, Goto H, Yaguchi K, Hashikawa T, Sano C, Shigemoto R, Nakashiba T, Itohara S (2014) Netrin-G/NGL complexes encode functional synaptic diversification. J Neurosci 34:15779-15792. CrossRef Medline

Miyake N, Chilton J, Psatha M, Cheng L, Andrews C, Chan WM, Law K, Crosier M, Lindsay S, Cheung M, Allen J, Gutowski NJ, Ellard S, Young E, Iannaccone A, Appukuttan B, Stout JT, Christiansen S, Ciccarelli ML, Baldi A, et al. (2008) Human CHN1 mutations hyperactivate alpha2chimaerin and cause Duane's retraction syndrome. Science 321:839-843. CrossRef Medline

Mizuno H, Luo W, Tarusawa E, Saito YM, Sato T, Yoshimura Y, Itohara S, Iwasato T (2014) NMDAR-regulated dynamics of layer 4 neuronal dendrites during thalamocortical reorganization in neonates. Neuron 82: 365-379. CrossRef Medline

Murai KK, Nguyen LN, Irie F, Yamaguchi Y, Pasquale EB (2003) Control of hippocampal dendritic spine morphology through ephrin-A3/EphA4 signaling. Nat Neurosci 6:153-160. CrossRef Medline

Naber PA, Lopes da Silva FH, Witter MP (2001) Reciprocal connections between the entorhinal cortex and hippocampal fields $\mathrm{CA} 1$ and the subiculum are in register with the projections from CA1 to the subiculum. Hippocampus 11:99-104. CrossRef Medline

Nakazawa T, Kuriu T, Tezuka T, Umemori H, Okabe S, Yamamoto T (2008) Regulation of dendritic spine morphology by an NMDA receptorassociated Rho GTPase-activating protein, p250GAP. J Neurochem 105: 1384-1393. CrossRef Medline

Nimchinsky EA, Oberlander AM, Svoboda K (2001) Abnormal development of dendritic spines in FMR1 knock-out mice. J Neurosci 21:51395146. Medline

Nimchinsky EA, Sabatini BL, Svoboda K (2002) Structure and function of dendritic spines. Annu Rev Physiol 64:313-353. CrossRef Medline

Nishimura-Akiyoshi S, Niimi K, Nakashiba T, Itohara S (2007) Axonal netrin-Gs transneuronally determine lamina-specific subdendritic segments. Proc Natl Acad Sci U S A 104:14801-14806. CrossRef Medline

Niwa H, Yamamura K, Miyazaki J (1991) Efficient selection for highexpression transfectants with a novel eukaryotic vector. Gene 108: 193-199. CrossRef Medline

Oh D, Han S, Seo J, Lee JR, Choi J, Groffen J, Kim K, Cho YS, Choi HS, Shin H, Woo J, Won H, Park SK, Kim SY, Jo J, Whitcomb DJ, Cho K, Kim H, Bae YC, Heisterkamp N, et al. (2010) Regulation of synaptic Rac1 activity, long-term potentiation maintenance, and learning and memory by BCR and ABR Rac GTPase-activating proteins. J Neurosci 30:1413414144. CrossRef Medline
Penzes P, Cahill ME, Jones KA, VanLeeuwen JE, Woolfrey KM (2011) Dendritic spine pathology in neuropsychiatric disorders. Nat Neurosci 14: 285-293. CrossRef Medline

Phillips RG, LeDoux JE (1992) Differential contribution of amygdala and hippocampus to cued and contextual fear conditioning. Behav Neurosci 106:274-285. CrossRef Medline

Ramakers GJ, Wolfer D, Rosenberger G, Kuchenbecker K, Kreienkamp HJ, Prange-Kiel J, Rune G, Richter K, Langnaese K, Masneuf S, Bösl MR, Fischer KD, Krugers HJ, Lipp HP, van Galen E, Kutsche K (2012) Dysregulation of Rho GTPases in the alphaPix/Arhgef6 mouse model of $\mathrm{X}$-linked intellectual disability is paralleled by impaired structural and synaptic plasticity and cognitive deficits. Hum Mol Genet 21:268-286. CrossRef Medline

Rampon C, Tang YP, Goodhouse J, Shimizu E, Kyin M, Tsien JZ (2000) Enrichment induces structural changes and recovery from nonspatial memory deficits in CA1 NMDAR1-knockout mice. Nat Neurosci 3:238 244. CrossRef Medline

Raynaud F, Moutin E, Schmidt S, Dahl J, Bertaso F, Boeckers TM, Homburger V, Fagni L (2014) Rho-GTPase-activating protein interacting with Cdc-42-interacting protein 4 homolog 2 (Rich2): a new Ras-related C3 botulinum toxin substrate 1 (Rac1) GTPase-activating protein that controls dendritic spine morphogenesis. J Biol Chem 289:2600-2609. CrossRef Medline

Shi L, Fu WY, Hung KW, Porchetta C, Hall C, Fu AK, Ip NY (2007) Alpha2chimaerin interacts with EphA4 and regulates EphA4-dependent growth cone collapse. Proc Natl Acad Sci U S A 104:16347-16352. CrossRef Medline

Shimshek DR, Kim J, Hübner MR, Spergel DJ, Buchholz F, Casanova E, Stewart AF, Seeburg PH, Sprengel R (2002) Codon-improved Cre recombinase (iCre) expression in the mouse. Genesis 32:19-26. CrossRef Medline

Van de Ven TJ, VanDongen HM, VanDongen AM (2005) The nonkinase phorbol ester receptor alpha 1-chimerin binds the NMDA receptor NR2A subunit and regulates dendritic spine density. J Neurosci 25:9488-9496. CrossRef Medline

van Praag H, Kempermann G, Gage FH (2000) Neural consequences of environmental enrichment. Nat Rev Neurosci 1:191-198. CrossRef Medline

Wegmeyer H, Egea J, Rabe N, Gezelius H, Filosa A, Enjin A, Varoqueaux F, Deininger K, Schnütgen F, Brose N, Klein R, Kullander K, Betz A (2007) EphA4-dependent axon guidance is mediated by the RacGAP alpha2chimaerin. Neuron 55:756-767. CrossRef Medline

Yang C, Kazanietz MG (2007) Chimaerins: GAPs that bridge diacylglycerol signalling and the small G-protein Rac. Biochem J 403:1-12. CrossRef Medline

Yuste R, Bonhoeffer T (2004) Genesis of dendritic spines: insights from ultrastructural and imaging studies. Nat Rev Neurosci 5:24-34. CrossRef Medline

Zhang H, Macara IG (2008) The PAR-6 polarity protein regulates dendritic spine morphogenesis through p190 RhoGAP and the Rho GTPase. Dev Cell 14:216-226. CrossRef Medline

Zhou L, Martinez SJ, Haber M, Jones EV, Bouvier D, Doucet G, Corera AT, Fon EA, Zisch AH, Murai KK (2007) EphA4 signaling regulates phospholipase $\mathrm{C} \gamma 1$ activation, cofilin membrane association, and dendritic spine morphology. J Neurosci 27:5127-5138. CrossRef Medline

Zuo Y, Lin A, Chang P, Gan WB (2005) Development of long-term dendritic spine stability in diverse regions of cerebral cortex. Neuron 46:181189. CrossRef Medline 